\title{
Synthesis, Antimicrobial and Cytotoxicity Studies of Some Novel Modified Strobilurin Derivatives
}

\author{
Ajjanna M. Sridhara, ${ }^{a, b}$ Kallam R. Venugopala Reddy, ${ }^{* b}$ Jathi Keshavayya, ${ }^{c}$ \\ Dasannana Malige S. Ambika, ${ }^{e}$ Vadiraj S. Gopinath, ${ }^{a}$ Prosenjit Bose, ${ }^{a}$ \\ Sanath Kumar Goud ${ }^{a}$ and Sanenahalli K. Peethambar ${ }^{d}$
}

\author{
${ }^{a}$ Advinus Therapeutics Pvt. Ltd, $21 \& 22$, Peenya II phase, Bangalore-560 058, India \\ ${ }^{b}$ Department of Studies in Industrial Chemistry, ${ }^{c}$ Department of Studies in Chemistry, \\ ${ }^{d}$ Department of Biochemistry, Kuvempu University, Jnana Sahyadri, \\ Shankaragatta-577 451, Karnataka, India \\ ${ }^{e}$ Department of Plant Pathology, G.K.V.K, UAS, Bangalore-65 India
}

\begin{abstract}
Uma série de novas 3-isoxazolinas substituídas, derivadas do metil-3-metóxi-2-(4-oxo-3,4diidroftalazin-1-il)prop-2-enoato foram estudadas e sintetizadas a partir do metil-(4-oxo-3,4diidroftalazin-1-il)acetato, o qual foi preparado a partir do anidrido ftálico. As estruturas dos novos compostos sintetizados foram caracterizadas por dados espectrais e suas atividades antimicrobianas e citotóxicas estudadas. Vários desses compostos mostraram boa atividade antimicrobiana.
\end{abstract}

A series of some new 3-isoxazoline substituted methyl-3-methoxy-2-(4-oxo-3,4dihydrophthalazin-1-yl)prop-2-enoate derivatives were designed and synthesized from methyl(4-oxo-3,4-dihydrophthalazin-1-yl)acetate, which in turn was prepared from phthalic anhydride. The structures of synthesized new compounds were characterized by spectral data and studied for their antimicrobial activities and cytotoxicity. Several of these compounds showed good antimicrobial activity.

Keywords: phthalazin-1(2H)-one, $\beta$-methoxyacrylate, strobilurins, isoxazoline

\section{Introduction}

Nitrogen-containing heterocyclic molecules constitute the largest portion of chemical entities, which are part of many natural products, fine chemicals, and biologically active pharmaceuticals. Strobilurins and their analogues constitute a large group of compounds that represent a new class of plant-protecting agents ${ }^{1}$ that meet all the demands that are made nowadays for pesticides. They exhibit efficacy against a broad-spectrum of fungal diseases, possess significant post-infective activity, and have a unique mode of action. ${ }^{2}$ Intensive studies aimed at a search for novel biologically active methoxyacrylate fungicides are currently under way by different manufacturers. ${ }^{3}$ Studies on the structure of natural methoxyacrylates have made possible to create a novel class of synthetic fungicides with enhanced stability, high activity, and a

*e-mail: venurashmi30@rediffmail.com broad spectrum of action. $\beta$-Methoxyacrylate which is a critical and common structural element of strobilurins, fund use in agrochemical agents, ${ }^{4}$ antivirals, ${ }^{5}$ antimalarials, ${ }^{6}$ and fungicides. ${ }^{7}$ There has been extensive industrial development of these compounds and their analogues. ${ }^{8,9} \mathrm{In}$ finding new $\beta$-methoxyacrylate derivatives, we observed that, phthalazines attached to these pharmacophore were not studied. Phthalazin-1(2H)-one derivatives are of considerable interest due to their antidiabetic, ${ }^{10}$ antiallergic, ${ }^{11}$ vasorelaxant, ${ }^{12}$ PDE4 inhibitor, ${ }^{13}$ VEGF (vascular endothelial growth factor) receptor tyrosine kinase (for the treatment of cancer), ${ }^{14}$ antiasthmatic, ${ }^{15}$ and herbicidal ${ }^{16}$ activities. A number of established drug molecules like Hydralazine, ${ }^{17,18}$ Budralazine, ${ }^{19,20}$ Azelastine, ${ }^{21,22}$ Ponalrestat, ${ }^{23}$ and Zopolrestat, ${ }^{24}$ were prepared from the corresponding phthalazinones.

Similarly, isoxazolines represents an important class of heterocyclic compounds with broad spectrum of biological activities. Substituted isoxazolines have revealed anti- 

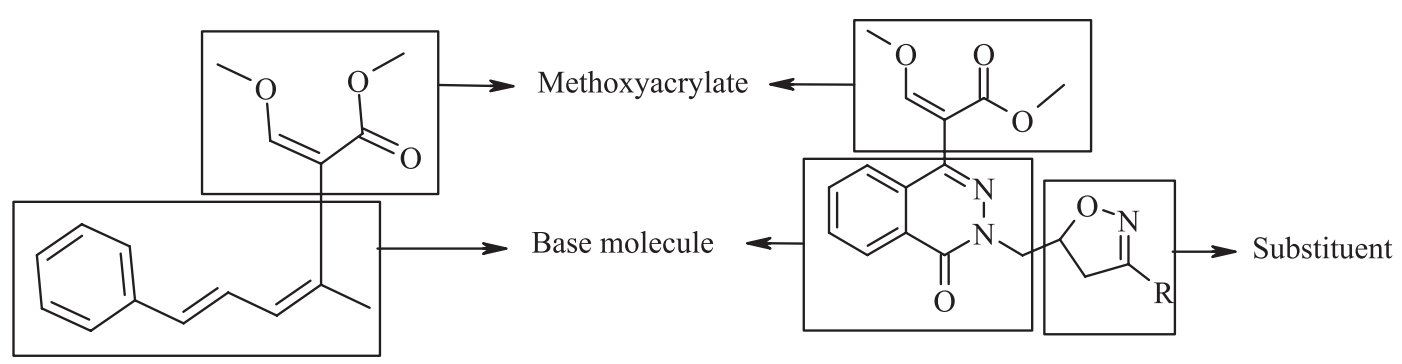

Figure 1. Strobilurin A and modified strobilurin derivatives.

influenza virus ${ }^{25}$ antifungal,${ }^{26}$ antitubercular, ${ }^{27}$ spermicidal and anti-HIV, ${ }^{28} \beta$-adrenergic receptor antagonist, ${ }^{29}$ analgesic and anti-inflammatory ${ }^{30}$ properties.

The diverse biological activities of $\beta$-methoxyacrylate, phthalazin-1(2H)-one, and isoxazoline pharmacophores envisaged us to plan a new lead compounds that may exhibit wide pharmacological activities. By combining these pharmacophore components in a molecule to give a compact system, we designed and synthesized a series of phthalazin-1 $(2 H)$-one derivatives containing $\beta$-methoxyacrylate and isoxazoline moieties. Figure 1 reveals a framework of these three important biological active pharmacophore component systems.

The synthesized new isoxazoline substituted phthalazinemethoxyacrylate derivatives were characterized by mass, IR and NMR studies. Purity of compounds was assessed by analytical HPLC and monitored by photodiode array (PDA) detector.

\section{Results and Discussion}

\section{Chemistry}

The core intermediate in the synthesis of targeted compounds 7a-l is methyl 2-(4-oxo-3,4-dihydrophthalazin1 -yl)acetate ${ }^{31}(4)$ which was prepared from phthalic anhydride (Scheme 1).

$N$-allylation of compound $\mathbf{4}$ with allyl bromide in presence of potassium carbonate as base gave methyl 2-(3-allyl-4oxo-3,4-dihydrophthalazin-1-yl)acetate (5). $\mathrm{N}$-allylation was confirmed by mass, IR, and NMR spectra. The active methylene part of phthalazin-1-yl acetate (5) was formylated with methylformate in presence of sodium hydride as base giving hydroxyacrylate intermediate, which then alkylated with dimethyl sulfate in presence of potassium carbonate to afford compound (6). The allyl function of compound 6 underwent 1,3 dipolar cyclization ${ }^{32}$ with aldoximes via nitrile oxide in presence of $\mathrm{N}$-chlorosuccinimide, dimethylformamide and potassium carbonate to give the desired compounds 7(a-l) (Scheme 2). The desired aldoximes were prepared by the condensation of hydroxyl amine hydrochloride with the corresponding aldehydes. ${ }^{33}$

\section{Biological study}

All the synthesized compounds were screened for their antibacterial activity against Staphylococcus aureus ( $S$. aureus), Bacillus subtilis (B. substilis), Salmonella typhi (S. typhi), and Escherichia coli (E. coli) and antifungal activity against Aspergillums niger (A. niger) and Candida albicans (C. albicans). Minimum inhibitory concentration (MIC) of all compounds was determined, which is defined as the lowest concentration of inhibitor at which bacterial growth was not visually apparent.

Investigation on antibacterial screening data (Table 1) showed some of the compounds were active against four human pathogenic bacteria. Compounds $\mathbf{7 a}, \mathbf{7 b}, \mathbf{7 c}, \mathbf{7 k}$ and $7 \mathbf{l}$ exhibited good activity against $S$. aureus. Similarly compounds $\mathbf{7 e}, \mathbf{7 h}$ and $\mathbf{7 l}$ showed activity against $B$. subtilis. The compounds $\mathbf{7 e}$ and $\mathbf{7 h}$ showed activity against $S$. typhi. Also the compounds $\mathbf{7 e}, \mathbf{7 h}$ and $\mathbf{7 k}$ showed activity against Escherichia coli. From these results it could be generalized that the thiophene substituted isoxazoline derivatives shows higher activity compared to other analogues.<smiles>O=C1OC(=O)c2ccccc21</smiles>

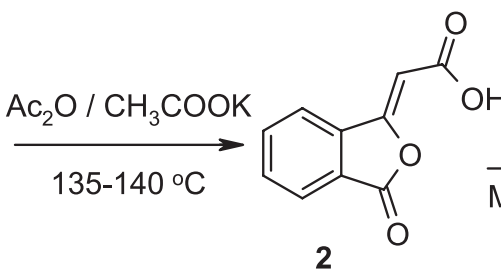

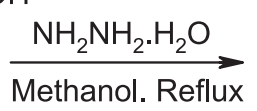<smiles>Cn1nc(CC(=O)O)c2ccccc2c1=O</smiles><smiles>COC(=O)Cc1n[nH]c(=O)c2ccccc12</smiles>

Scheme 1. Synthesis of methyl 2-(4-oxo-3,4-dihydrophthalazin-1-yl)acetate. 
<smiles>C=CC(Br)(Br)C(C(=O)OC)C(C)(C)C(F)(F)F</smiles><smiles>C=CCn1nc(CC(=O)OC)c2ccccc2c1=O</smiles><smiles>C=CCn1nc(/C(=C/O)C(=O)OC)c2ccccc2c1=O</smiles><smiles>[R]C1=NOC(Cn2nc(/C(=C/OC)C(=O)OC)c3ccccc3c2=O)C1</smiles><smiles>C=CCn1nc(C(=COC)C(=O)OC)c2ccccc2c1=O</smiles>

\begin{tabular}{lllllllll}
\multicolumn{2}{c}{ R } & R & R & R & \\
7a & methyl & 7d & fluorophenyl & $\mathbf{7 g}$ & 3-(fluorophenoxy)phenyl & $\mathbf{7 j}$ & 1-pivaloylpiperidin-4-yl \\
7b & phenyl & $\mathbf{7 e}$ & 4-methylphenyl & $\mathbf{7 h}$ & thiophen-2-yl & $\mathbf{7 k}$ & 1-benzylpiperidon-4-yl \\
$\mathbf{7 c}$ & 4-chlorophenyl & $\mathbf{7 f}$ & 3,4-dimethoxyphenyl & $\mathbf{7 i}$ & 4-bromo-3-fluorophenyl & $\mathbf{7 l}$ & 2-hydroxyphenyl
\end{tabular}

Scheme 2. Synthesis of 3-isoxazoline substituted phthalazine-methoxyacrylate derivatives 7(a-1).

The antifungal results (Table 1) revealed that the synthesized compounds showed variable degree of inhibition against the tested fungi. Compounds $\mathbf{7 c}, \mathbf{7 d}, \mathbf{7 g}$ and $7 \mathbf{h}$ possessed the good antifungal activity against $A$. niger and C. albicans. From the results it was concluded that the thiophene substituted isoxazoline compounds showed better activity.

\section{Cytotoxicity assay}

MTT cell viability assay ${ }^{34}$ was performed to study the cytotoxicity effect of newly synthesized compounds $7(\mathbf{a}-\mathbf{l})$ against Calu- 6 cells at $50 \mu \mathrm{M}$ concentration using 96-well tissue culture plates. As observed in the results (Table 2), the in vitro cytotoxicity assay did not show any reduction in the growth rate. This is reflected by the cell number and the degree of inhibition of growth, thus the assay provided indication that the tested compunds are not cytotoxic.

\section{Conclusions}

In this article we report the synthesis of new 3-isoxazoline substituted modified strobilurin phthalazinemethoxyacrylate derivatives (7a-1), starting from commercially available phthalic anhydride. Investigation of their antimicrobial activity revealed that phthalazine with a thiophene substitution (7h) was the most active compound although it was significantly less than that of positive control. Also the cytotoxicity assay showed the compounds were non toxic.

\section{Experimental}

All chemicals used for the synthesis were of analytical grade and were procured from Sigma Aldrich Chemical Co, Bangalore, India and the intermediates were prepared as per known literature procedures. ${ }^{1} \mathrm{H}$ NMR spectra were recorded on a $400 \mathrm{MHz}$ Varian-AS NMR spectrometer using TMS as an internal standard. IR spectra were recorded by using Perkin Elmer 100 Series FT-IR spectrometer. Mass spectra were recorded on an Agilent 1200 Series LC/MSD VL system. Melting points were determined by using Buchi melting point B-545 instrument and are uncorrected. All the reactions were monitored by thin layer chromatography (TLC) using Merck pre coated TLC silica gel plates. The crude compounds were purified by using CombiFlash ${ }^{\circledR}$ Companion Flash Chromatography, Teledyne, ISCO, USA. 
HPLC method for compounds 7(a-l): The purity of compounds was assessed by HPLC methods using an Agilent 1200 series LC system. The mobile phase was 10 mmol ammonium acetate adjusted to $\mathrm{pH} 3.0$ with acetic acid (A) and acetonitrile (B). The column was an Inertsil ODS-3V $(250 \times 4.6 \mathrm{~mm}, 5 \mu$ particle size $)$ and a PDA Detector was employed in the UV range $190-490 \mathrm{~nm}$. Gradient elution was performed, according to the following protocol: 0-2 $\min$ : 50\% B; 2-10 min: 50-90\% B; 10-20 min: 90\% B; 20-25 min: $90-50 \%$ B and 25-30 min: 50\% B.

\section{Preparation of methyl 2-(3-allyl-4-oxo-3,4-dihydro- phthalazin-1-yl)acetate (5)}

Allyl bromide ( $60.5 \mathrm{~g}, 0.5 \mathrm{~mol})$ was added to a stirred solution of methyl 2-(4-oxo-3,4-dihydrophthalazin-1-yl) acetate (4) $(21.8 \mathrm{~g}, 0.10 \mathrm{~mol})$ in dimethylformamide $(250 \mathrm{~mL})$ and potassium carbonate $(69.0 \mathrm{~g}, 0.5 \mathrm{~mol})$ at room temperature and heated to $60-65{ }^{\circ} \mathrm{C}$ for $6 \mathrm{~h}$. After completion of reaction, filtered the inorganics, the filtrate obtained was distilled completely under reduced pressure at $60-65{ }^{\circ} \mathrm{C}$. The residue obtained was diluted with ice water $(500 \mathrm{~mL})$ and stirred for $30 \mathrm{~min}$. The precipitated product was filtered, dried and recrystallised using isopropyl alcohol to yield $\mathbf{5}$ as white solid. Yield $86 \%$; mp $90.2-94.8{ }^{\circ} \mathrm{C}$; MS (ESI) $m / z: 259.1(\mathrm{M}+\mathrm{H})^{+}$; Purity $98.67 \%$; ${ }^{1} \mathrm{H}$ NMR (400 MHz, DMSO- $d_{6}$ ) $\delta 3.64$ (s, 3H, $\mathrm{CH}_{3}$ ), $4.11(\mathrm{~s}, 2 \mathrm{H}$, $\left.\mathrm{CH}_{2}\right), 4.73\left(\mathrm{~d}, J 5.6 \mathrm{~Hz}, \mathrm{CH}_{2}\right), 5.08-5.19\left(\mathrm{~m}, 2 \mathrm{H}, \mathrm{CH}_{2}\right)$, 5.94-6.04 (m, 1H, CH), 7.87-7.92 (m, 3H, Ar-H), 8.30-8.32 (m, 1H, Ar-H); IR (KBr) $v_{\text {max }} / \mathrm{cm}^{-1}: 3012,1708,1675,1599$.

Preparation of methyl 2-(3-allyl-4-oxo-3,4-dihydrophthalazin-1-yl)-3-methoxy acrylate (6)

A solution of compound $5(20.0 \mathrm{~g}, 0.077 \mathrm{~mol})$ in methylformate $(100 \mathrm{~g}, 1.66 \mathrm{~mol})$ and dimethylformamide $(40 \mathrm{~mL})$ was added slowly to the slurry of sodium hydride $(60 \%$ paste in paraffin oil) $(6.0 \mathrm{~g}, 0.15 \mathrm{~mol})$ in dimethylformamide $(200 \mathrm{~mL})$ at $0-5{ }^{\circ} \mathrm{C}$ in $1 \mathrm{~h}$ under nitrogen atmosphere. After complete addition, the reaction mixture was stirred for $6 \mathrm{~h}$ at $0-10^{\circ} \mathrm{C}$. After of the reaction, it was quenched by addition of saturated solution of ammonium chloride, ethyl acetate $(250 \mathrm{~mL})$ was added and the organic layer was separated. The aqueous layer was extracted with ethyl acetate $(3 \times 100 \mathrm{~mL})$. The combined organic layers were washed with sat. sodium chloride, and dried with anhydrous sodium sulfate. After filtration, the solvent was completely evaporated under reduced pressure and the residue was in dimethylformamide $(200 \mathrm{~mL})$ and cooled to $5-10^{\circ} \mathrm{C}$. Potassium carbonate $(21.2 \mathrm{~g}, 0.154 \mathrm{~mol})$, and dimethyl sulfate $(19.7 \mathrm{~g}, 0.153 \mathrm{~mol})$ were added to the solution at $0-10{ }^{\circ} \mathrm{C}$, and stirred for $8 \mathrm{~h}$ at ambient temperature. After completion of reaction, the reaction mass was filtered and the filtrate was evaporated under reduced pressure. The residue was diluted with water, extracted with ethyl acetate $(3 \times 100 \mathrm{~mL})$, washed with water, dried with anhydrous sodium sulfate. After filtration the solvent was evaporated under reduced pressure to afford the crude product, which was purified by column chromatography with ethyl acetate/hexane (1:5) to get $15.2 \mathrm{~g}$ of compound (6) as a white solid. Yield 65\%; mp 129.0-132.2 ${ }^{\circ} \mathrm{C}$; MS (ESI) $m / z: 301.1(\mathrm{M}+\mathrm{H})^{+}$; Purity 98.99\%; ${ }^{1} \mathrm{H}$ NMR (400 $\left.\mathrm{MHz}, \mathrm{DMSO}-d_{6}\right) \delta 3.60\left(\mathrm{~s}, 3 \mathrm{H}, \mathrm{CH}_{3}\right), 3.85\left(\mathrm{~s}, 3 \mathrm{H}, \mathrm{CH}_{3}\right)$, $4.74\left(\mathrm{~d}, J 4.8 \mathrm{~Hz}, 2 \mathrm{H}, \mathrm{CH}_{2}\right), 5.08-5.19\left(\mathrm{~m}, 2 \mathrm{H}, \mathrm{CH}_{2}\right)$, 5.94-6.03 (m, 1H, CH), 7.62-7.64 (m, 1H, Ar-H), 7.85$7.94(\mathrm{~m}, 2 \mathrm{H}, \mathrm{Ar}-\mathrm{H}), 7.97(\mathrm{~s}, 1 \mathrm{H},=\mathrm{CH}), 8.29-8.31(\mathrm{~m}, 1 \mathrm{H}$, Ar-H); IR (KBr) $v_{\max } / \mathrm{cm}^{-1}: 2956,1747,1658$.

General method for the preparation of 3-isoxazoline substituted phthalazine-methoxyacrylate derivatives $7(\boldsymbol{a}-\mathrm{l})$

A mixture of aldoxime ( $10.0 \mathrm{mmol}), N$-chlorosuccinimide $(11.0 \mathrm{mmol})$ and potassium carbonate $(15.0 \mathrm{mmol})$ were slurred in dimethylformamide $(10 \mathrm{~mL})$ and heated to $60^{\circ} \mathrm{C}$ for $30 \mathrm{~min}$. The compound $6(8.0 \mathrm{mmol})$ was added, and continued the heating for $4 \mathrm{~h}$. After completion of reaction, cooled, diluted with water $(50 \mathrm{~mL})$ and extracted with ethyl acetate $(3 \times 50 \mathrm{~mL})$. After drying with anhydrous sodium sulfate and filtration, the solvent was evaporated to provide the crude product, which was purified by using flash chromatography eluting with ethyl acetate / hexane (1: 5) to get the corresponding phthalazine derivatives 7a-l.

Methyl 3-methoxy-2-(3-((3-methyl-4,5-dihydroisoxazol5-yl)methyl)-4-oxo-3,4-dihydrophthalazin-1-yl)acrylate (7a). Yield 64\%; Purity 93.7\%; White solid; mp 125.1$129.2{ }^{\circ} \mathrm{C}$; MS (ESI) $\mathrm{m} / z: 358.1(\mathrm{M}+\mathrm{H})^{+} ;{ }^{1} \mathrm{H}$ NMR $(400$ MHz, DMSO- $\left.d_{6}\right) \delta 1.92\left(\mathrm{~s}, 3 \mathrm{H},-\mathrm{C}-\mathrm{CH}_{3}\right), 3.07-3.35(2 \mathrm{~m}$, $\left.2 \mathrm{H}, \mathrm{CH}_{2}\right), 3.67\left(\mathrm{~s}, 3 \mathrm{H}, \mathrm{COOCH}_{3}\right), 3.97\left(\mathrm{~s}, 3 \mathrm{H}, \mathrm{OCH}_{3}\right)$, 4.02-4.40 (2m, $\left.2 \mathrm{H}, \mathrm{CH}_{2}\right), 4.83-4.95(\mathrm{~m}, 1 \mathrm{H}$, oxazole $\mathrm{CH})$, 7.61-7.63 (m, 1H, Ar-H), 7.85-7.93 (m, 2H, Ar-H), 7.94 (s, $1 \mathrm{H},=\mathrm{CH}), 8.29-8.31(\mathrm{~m}, 1 \mathrm{H}, \mathrm{Ar}-\mathrm{H}) ;{ }^{13} \mathrm{C}$ NMR $(100 \mathrm{MHz}$, DMSO- $\left.d_{6}\right) \delta 177.8,166.7,160.8,159.7,140.5,133.1$, 131.7, 131.5, 129.8, 127.8, 126.9, 125.7, 62.5, 53.3, 51.8, $38.2,29.6$; IR (KBr) $v_{\max } / \mathrm{cm}^{-1}: 2950,1761,1654$.

Methyl 3-methoxy-2-(4-oxo-3-((3-phenyl-4,5dihydroisoxazol-5-yl)methyl)-3,4-dihy drophthalazin-1-yl) acrylate ( $7 \boldsymbol{b})$. Yield 71\%; Purity 96.6\%; White solid; mp 179.2-181.4 ${ }^{\circ} \mathrm{C}$; MS (ESI) $m / z: 420.1(\mathrm{M}+\mathrm{H})^{+} ;{ }^{1} \mathrm{H}$ NMR $\left(400 \mathrm{MHz}, \mathrm{DMSO}-d_{6}\right) \delta 3.34-3.55\left(2 \mathrm{~m}, 2 \mathrm{H}, \mathrm{CH}_{2}\right), 3.59$ (s, $\left.3 \mathrm{H}, \mathrm{CH}_{3}\right), 3.82\left(\mathrm{~s}, 3 \mathrm{H}, \mathrm{CH}_{3}\right), 4.10-4.48\left(2 \mathrm{~m}, 2 \mathrm{H}, \mathrm{CH}_{2}\right)$, 
5.08-5.15 (m, 1H, oxazole-CH), 7.42-7.44 (m, 3H, Ar-H), 7.59-7.64 (m, 3H, Ar-H), 7.83-7.91 (m, 2H, Ar-H), 7.94 (s, $1 \mathrm{H},=\mathrm{CH}), 8.27-8.30(\mathrm{~m}, 1 \mathrm{H}, \mathrm{Ar}-\mathrm{H}) ;{ }^{13} \mathrm{C}$ NMR $(100 \mathrm{MHz}$, DMSO- $\left.d_{6}\right) \delta 177.9,166.7,164.9,163.3,162.4,159.6$, 155.5, 140.5, 133.0, 131.5,129.8, 128.9, 127.8, 126.8, 125.7, 125.6, 105.6, 62.4, 53.3, 51.8, 38.2, 29.5; IR (KBr) $\mathrm{v}_{\max } / \mathrm{cm}^{-1}: 2951,1762,1654$.

Methyl 2-(3-((3-(4-chlorophenyl)-4,5-dihydroisoxazol5-yl)methyl)-4-oxo-3,4-dihydrophthalazin-1-yl)-3methoxyacrylate (7c). Yield 72\%; Purity 97.1\%; White solid; mp 162.0-164.7 ${ }^{\circ} \mathrm{C}$; MS (ESI) $m / z: 454.1(\mathrm{M}+\mathrm{H})^{+}$; ${ }^{1} \mathrm{H}$ NMR (400 MHz, DMSO- $\left.d_{6}\right) \delta 3.35-3.56(2 \mathrm{~m}, 2 \mathrm{H}$, $\left.\mathrm{CH}_{2}\right), 3.57\left(\mathrm{~s}, 3 \mathrm{H}, \mathrm{CH}_{3}\right), 3.85\left(\mathrm{~s}, 3 \mathrm{H}, \mathrm{CH}_{3}\right), 4.15-4.51(2 \mathrm{~m}$, $\left.2 \mathrm{H}, \mathrm{CH}_{2}\right), 5.14-5.19(\mathrm{~m}, 1 \mathrm{H}$, oxazole- $\mathrm{CH}) 7.54(\mathrm{~d}, J 8.4$ $\mathrm{Hz}, 2 \mathrm{H}, \mathrm{Ar}-\mathrm{H}$ ), 7.63-7.68 (m, 3H, Ar-H), 7.89 (d, J 8.4Hz, 2H, Ar-H), 7.94 (s, 1H, C=CH), 8.31-8.33 (m, 1H, Ar-H); ${ }^{13} \mathrm{C}$ NMR (100 MHz, DMSO- $\left.d_{6}\right) \delta 177.4,166.6,164.6$, $163.7,162.9,159.2,155.5,140.4,133.1,131.0,129.6$, 128.8, 127.9, 126.8, 125.7, 125.5, 105.6, 62.3, 53.7, 51.2, 38.4, 29.7; IR (KBr) $v_{\max } / \mathrm{cm}^{-1}: 2989,1760,1681,1542$.

Methyl 2-(3-((3-(4-fluorophenyl)-4,5-dihydroisoxazol5-yl)methyl)-4-oxo-3,4-dihydrophthalazin-1-yl)-3methoxyacrylate (7d). Yield 58\%; Purity 96.4\%; White solid; mp 129.3-131.9 ${ }^{\circ} \mathrm{C}$; MS (ESI) $m / z: 438.1(\mathrm{M}+\mathrm{H})^{+}$; ${ }^{1} \mathrm{H}$ NMR (400 MHz, DMSO- $\left.d_{6}\right) \delta 3.36-3.42(2 \mathrm{~m}, 2 \mathrm{H}$, $\left.\mathrm{CH}_{2}\right), 3.71\left(\mathrm{~s}, 3 \mathrm{H}, \mathrm{CH}_{3}\right), 3.87$ (s, $\left.3 \mathrm{H}, \mathrm{CH}_{3}\right), 4.39-4.60(2 \mathrm{~m}$, $\left.2 \mathrm{H}, \mathrm{CH}_{2}\right), 5.28-5.32(\mathrm{~m}, 1 \mathrm{H}$, oxazole- $\mathrm{CH})$ 7.05-7.14 (m, $2 \mathrm{H}, \mathrm{Ar}-\mathrm{H}), 7.54-7.56(\mathrm{~m}, 1 \mathrm{H}, \mathrm{Ar}-\mathrm{H})$, 7.64-7.68 (m, $2 \mathrm{H}$, Ar-H), 7.76-7.78 (m, 2H, Ar-H), 7.82 (s, 1H, C=CH), 8.45-8.47 (m, $1 \mathrm{H}, \mathrm{Ar}-\mathrm{H}) ;{ }^{13} \mathrm{C}$ NMR (100 MHz, DMSO- $\left.d_{6}\right)$ $\delta 177.8,166.8,164.9,163.4,162.4,159.7,155.6,140.6$, $133.1,129.7,128.8,127.8,126.9,125.7,125.6,115.8$, 105.6, 62.5, 53.3, 51.8, 38.2, 29.6; IR (KBr) $v_{\max } / \mathrm{cm}^{-1}$ : 2956, 1761, 1654.

Methyl 3-methoxy-2-(3-((3-(4-methoxyphenyl)4,5-dihydroisoxazol-5-yl) methyl)-4-oxo-3,4-dihydrophthalazin-1-yl)acrylate (7e). Yield 45\%; Purity 96.7\%; White solid; mp $126-129^{\circ} \mathrm{C}$; MS (ESI) $m / z: 450.1(\mathrm{M}+\mathrm{H})^{+}$; ${ }^{1} \mathrm{H}$ NMR (400 MHz, DMSO- $\left.d_{6}\right) \delta 3.36-3.37$ and 3.66-3.72 (2m, 2H, $\left.\mathrm{CH}_{2}\right), 3.63\left(\mathrm{~s}, 3 \mathrm{H}, \mathrm{CH}_{3}\right), 3.80\left(\mathrm{~s}, 3 \mathrm{H}, \mathrm{CH}_{3}\right), 3.95$ (s, 3H, $\left.\mathrm{CH}_{3}\right), 4.13-4.46\left(2 \mathrm{~m}, 2 \mathrm{H}, \mathrm{CH}_{2}\right), 5.08-5.14(\mathrm{~m}, 1 \mathrm{H}$, oxazole-CH), 7.01 (d, J 8.4 Hz, 2H, Ar-H), 7.59 (d, J 8.4 $\mathrm{Hz}, 2 \mathrm{H}, \mathrm{Ar}-\mathrm{H})$, 7.64-7.65 (m, 1H, Ar-H), 7.87-7.94 (m, $2 \mathrm{H}, \mathrm{Ar}-\mathrm{H}), 7.95$ (s, 1H, C=CH), 8.31-8.33 (m, 1H, Ar-H); ${ }^{13} \mathrm{C}$ NMR (100 MHz, DMSO- $\left.d_{6}\right) \delta 177.9,166.8,164.9$, 163.4, 162.4, 159.7, 155.7, 140.3, 133.5, 131.7, 129.6, $128.8,127.8,126.8,125.9,125.5,105.5,62.5,55.7,53.3$, $51.8,38.2,29.6$; IR (KBr) $v_{\max } / \mathrm{cm}^{-1}: 2979,2815,1673$.
Methyl 2-(3-((3-(3,4-dimethoxyphenyl)-4,5-dihydroisoxazol-5-yl)methyl)-4-oxo-3,4-dihydrophthalazin-1yl)-3-methoxyacrylate (7f). Yield 45\%; Purity 95.3\%; Off-white solid; mp 120.1-125.2 ${ }^{\circ} \mathrm{C}$; MS (ESI) $\mathrm{m} / z: 480.1$ $(\mathrm{M}+\mathrm{H})^{+} ;{ }^{1} \mathrm{H}$ NMR $\left(400 \mathrm{MHz}, \mathrm{DMSO}-d_{6}\right) \delta 3.45-3.56$ $\left(2 \mathrm{~m}, 2 \mathrm{H}, \mathrm{CH}_{2}\right), 3.63$ (s, $\left.3 \mathrm{H}, \mathrm{CH}_{3}\right), 3.80\left(\mathrm{~s}, 9 \mathrm{H}, 3 \times \mathrm{CH}_{3}\right)$, 3.97-4.44 (2m, 2H, $\left.\mathrm{CH}_{2}\right), 5.10-5.12(\mathrm{~m}, 1 \mathrm{H}$, oxazole- $\mathrm{CH})$, 7.09-7.12 (m, 2H, Ar-H), 7.50-7.55 (m, 4H, Ar-H), 7.94 (s, 1H, C=CH), 8.30-8.34 (m, 1H, Ar-H); ${ }^{13} \mathrm{C}$ NMR (400 MHz, DMSO- $\left.d_{6}\right) \delta 177.7,166.6,164.7,163.5,162.3,159.7$, 155.7, 140.2, 133.6, 131.6, 129.8, 128.9, 127.7, 126.8, 125.9, 125.5, 105.4, 62.5, 55.6, 55.5, 53.3, 51.8, 38.2, 29.5; IR (KBr) $v_{\text {max }} / \mathrm{cm}^{-1}: 2979,2815,1760,1673$.

Methyl 2-(3-((3-(3-(4-fluorophenoxy)phenyl)-4,5dihydroisoxazol-5-yl) methyl)-4-oxo-3,4-dihydrophthalazin-1-yl)-3-methoxyacrylate (7g). Yield 53\%; Purity 94.2\%; Brown solid; mp 137.5-140.2 ${ }^{\circ} \mathrm{C}$; MS (ESI) $m / z: 530.1(\mathrm{M}+\mathrm{H})^{+} ;{ }^{1} \mathrm{H}$ NMR $\left(400 \mathrm{MHz}\right.$, DMSO- $\left.d_{6}\right) \delta 3.31-$ $3.53\left(2 \mathrm{~m}, 2 \mathrm{H}, \mathrm{CH}_{2}\right), 3.57\left(\mathrm{~s}, 3 \mathrm{H}, \mathrm{CH}_{3}\right), 3.86\left(\mathrm{~s}, 3 \mathrm{H}, \mathrm{CH}_{3}\right)$, 4.15-4.46 (2m, 2H, $\left.\mathrm{CH}_{2}\right), 5.15-5.16(\mathrm{~m}, 1 \mathrm{H}$, oxazole- $\mathrm{CH})$, 7.02-7.07 (m, 3H, Ar-H), 7.15-7.20 (m, 1H, Ar-H), 7.437.93 (m, 5H, Ar-H), 7.64-7.93 (m, 2H, Ar-H), 7.94 (s, 1H, $\mathrm{C}=\mathrm{CH}), 8.29-8.32(\mathrm{~m}, 1 \mathrm{H}, \mathrm{Ar}-\mathrm{H}) ;{ }^{13} \mathrm{C}$ NMR $(100 \mathrm{MHz}$, $\left.\mathrm{CDCl}_{3}\right) \delta 177.7,166.6,164.7,163.9,162.3,159.5,156.7$, 156.6, 155.2, 153.2, 144.2, 140.2, 139.9, 133.7, 132.0, $129.8,128.5,127.8,127.5,126.4,124.0,125.5,105.4$, $62.5,53.3,51.8,38.2,29.6$; IR $(\mathrm{KBr}) v_{\max } / \mathrm{cm}^{-1}: 2970$, $2830,1761,1673$.

Methyl 3-methoxy-2-(4-oxo-3-((3-(thiophen-2-yl)4,5-dihydroisoxazol-5-yl) methyl)-3,4-dihydrophthalazin1-yl)acrylate (7h). Yield 70\%; Purity 94.6\%; Off-white solid; mp 143.2-148.6 ${ }^{\circ} \mathrm{C}$; MS (ESI) $m / z: 426.1(\mathrm{M}+\mathrm{H})^{+}$; ${ }^{1} \mathrm{H} \mathrm{NMR}\left(400 \mathrm{MHz}, \mathrm{DMSO}-d_{6}\right) \delta 3.36-3.56\left(2 \mathrm{~m}, 2 \mathrm{H}, \mathrm{CH}_{2}\right)$, $3.63\left(\mathrm{~s}, 3 \mathrm{H}, \mathrm{CH}_{3}\right), 3.86\left(\mathrm{~s}, 3 \mathrm{H}, \mathrm{CH}_{3}\right), 4.16-4.48(2 \mathrm{~m}, 2 \mathrm{H}$, $\left.\mathrm{CH}_{2}\right)$, 5.12-5.19 (m, $1 \mathrm{H}$, oxazole- $\left.\mathrm{CH}\right) 7.15-7.17(\mathrm{~m}, 1 \mathrm{H}$, Ar-H), $7.36(\mathrm{~d}, J 3.6 \mathrm{~Hz}, 1 \mathrm{H}, \mathrm{Ar}-\mathrm{H}), 7.63-7.65(\mathrm{~m}, 1 \mathrm{H}$, Ar-H), $7.70(\mathrm{~d}, J 5.2 \mathrm{~Hz}, 1 \mathrm{H}, \mathrm{Ar}-\mathrm{H}), 7.74-7.94(\mathrm{~m}, 2 \mathrm{H}$, $\mathrm{Ar}-\mathrm{H}), 7.95$ (s, $1 \mathrm{H}, \mathrm{C}=\mathrm{CH}), 8.31-8.33(\mathrm{~m}, 1 \mathrm{H}, \mathrm{Ar}-\mathrm{H}) ;{ }^{13} \mathrm{C}$ NMR (100 MHz, DMSO- $\left.d_{6}\right) \delta 177.4,166.6,164.6,163.7$, 162.9, 159.2, 140.4, 133.1, 131.0, 129.6, 127.9, 126.8, 125.7, 125.5, 105.6, 62.3, 53.7, 51.2, 38.4, 29.7; IR (KBr) $v_{\max } / \mathrm{cm}^{-1}: 2972,2835,1768,1675$.

Methyl 2-(3-((3-(4-bromo-3-fluorophenyl)-4,5dihydroisoxazol-5-yl)methyl)-4-oxo-3,4-dihydrophthalazin-1-yl)-3-methoxyacrylate (7i). Yield 59\%; Purity 95.4\%; White solid; mp 133.5-137.2 ${ }^{\circ} \mathrm{C}$; MS (ESI) $\mathrm{m} / z$ : $516.1(\mathrm{M}+\mathrm{H})^{+} ;{ }^{1} \mathrm{H}$ NMR $\left(400 \mathrm{MHz}\right.$, DMSO- $\left.d_{6}\right) \delta 3.31-$ $3.55\left(2 \mathrm{~m}, 2 \mathrm{H}, \mathrm{CH}_{2}\right), 3.62\left(\mathrm{~s}, 3 \mathrm{H}, \mathrm{CH}_{3}\right), 3.85\left(\mathrm{~s}, 3 \mathrm{H}, \mathrm{CH}_{3}\right)$, 
4.19-4.49 (2m, 2H, $\left.\mathrm{CH}_{2}\right)$, 5.28-5.32 (m, 1H, oxazole- $\left.\mathrm{CH}\right)$ 7.32-7.37 (m, 1H, Ar-H), 7.63-7.69 (m, 2H, Ar-H), 7.82$7.92(\mathrm{~m}, 3 \mathrm{H}, \mathrm{Ar}-\mathrm{H}), 7.95(\mathrm{~s}, 1 \mathrm{H}, \mathrm{C}=\mathrm{CH}), 8.31-8.33(\mathrm{~m}, 1 \mathrm{H}$, Ar-H). ${ }^{13} \mathrm{C}$ NMR (100 MHz, DMSO- $\left.d_{6}\right) \delta 177.3,166.6$, 164.8, 163.4, 162.3, 159.6, 155.6, 140.5, 133.2, 129.6, $128.9,127.8,126.9,125.7,125.5,115.9,105.5,62.4,53.2$, 51.7, 38.2, 29.4; IR (KBr) $v_{\max } / \mathrm{cm}^{-1} 2989,1763,1652$.

Methyl 3-methoxy-2-(4-oxo-3-((3-(1-pivaloylpiperidin-4-yl)-4,5-dihydro isoxazol-5-yl)methyl)-3,4dihydrophthalazin-1-yl)acrylate (7j). Yield 56\%; Purity 95.6\%; White solid; mp 163.3-167.9 ${ }^{\circ} \mathrm{C}$. MS (ESI) $m / z: 511.2(\mathrm{M}+\mathrm{H})^{+} ;{ }^{1} \mathrm{H}$ NMR $\left(400 \mathrm{MHz}\right.$, DMSO- $\left.d_{6}\right) \delta$ $1.27\left(\mathrm{~s}, 9 \mathrm{H}, 3 \mathrm{CH}_{3}\right), 1.51-1.61\left(\mathrm{~m}, 2 \mathrm{H}\right.$, piperidine $\left.\mathrm{CH}_{2}\right)$, 1.82-1.91 $\left(\mathrm{m}, 2 \mathrm{H}\right.$, piperidine $\left.\mathrm{CH}_{2}\right), 2.63-2.70(\mathrm{~m}, 1 \mathrm{H}$, piperidine $\mathrm{CH}), 2.89-2.98\left(\mathrm{~m}, 2 \mathrm{H}\right.$, Piperidine $\left.\mathrm{N}-\mathrm{CH}_{2}\right)$, 2.99-3.05 (m, $\left.2 \mathrm{H}, \mathrm{CH}_{2}\right) ; 3.71\left(\mathrm{~s}, 3 \mathrm{H}, \mathrm{CH}_{3}\right) ; 3.87(\mathrm{~s}, 3 \mathrm{H}$, $\left.\mathrm{CH}_{3}\right)$; 4.28-4.39 (m, $2 \mathrm{H}$, piperidine $\left.\mathrm{N}-\mathrm{CH}_{2}\right), 4.40-4.48$ $\left(\mathrm{m}, 2 \mathrm{H}, \mathrm{CH}_{2}\right) ; 5.07-5.14(\mathrm{~m}, 1 \mathrm{H}$, oxazole- $\mathrm{CH}), 7.52-$ $7.56(\mathrm{~m}, 1 \mathrm{H}, \mathrm{Ar}-\mathrm{H}), 7.74-7.79(\mathrm{~m}, 2 \mathrm{H}, \mathrm{Ar}-\mathrm{H}), 7.82(\mathrm{~s}$, $1 \mathrm{H}, \mathrm{C}=\mathrm{CH}), 8.44-8.45(\mathrm{~m}, 1 \mathrm{H}, \mathrm{Ar}-\mathrm{H}) ;{ }^{13} \mathrm{C}$ NMR $(100$ MHz, DMSO- $\left.d_{6}\right) \delta 176.2,166.7,163.3,160.8,159.7$, $140.5,133.1,131.6,131.5,129.6,127.8,126.9,125.7$, 62.5, 53.0, 51.8, 44.7, 38.6, 35.6, 29.4, 28.3; IR (KBr) $v_{\max } / \mathrm{cm}^{-1}: 2948,1710,1651$.

Methyl 2-(3-((3-(1-benzylpiperidin-4-yl)-4,5-dihydroisoxazol-5-yl)methyl)-4-oxo-3,4-dihydrophthalazin-1yl)-3-methoxyacrylate (7k). Yield 45\%; Purity 95.9\%; White solid; mp 158.3-161.9 ${ }^{\circ} \mathrm{C}$; MS (ESI) $\mathrm{m} / z: 517.1$ $(\mathrm{M}+\mathrm{H})^{+} ;{ }^{1} \mathrm{H}$ NMR $\left(400 \mathrm{MHz}, \mathrm{DMSO}-d_{6}\right) \delta 1.49-1.56(\mathrm{~m}$, $2 \mathrm{H}$, piperidine $\left.\mathrm{CH}_{2}\right), 1.73-1.76\left(\mathrm{~m}, 2 \mathrm{H}\right.$, piperidine $\mathrm{CH}_{2}$ ), $2.02(\mathrm{~m}, 1 \mathrm{H}$, piperidine $\mathrm{CH}), 2.33\left(\mathrm{~s}, 2 \mathrm{H}, \mathrm{CH}_{2}\right), 2.36-2.41$ $\left(\mathrm{m}, 2 \mathrm{H}\right.$, piperidine $\left.\mathrm{N}-\mathrm{CH}_{2}\right), 2.81-2.87(\mathrm{~m}, 2 \mathrm{H}$, piperidine $\left.\mathrm{CH}_{2}\right), 2.88-3.10\left(2 \mathrm{~m}, 2 \mathrm{H}, \mathrm{CH}_{2}\right), 3.63\left(\mathrm{~s}, 3 \mathrm{H},-\mathrm{OCH}_{3}\right), 3.86$ (s, $\left.3 \mathrm{H},-\mathrm{CH}_{3}\right), 3.95-4.39\left(2 \mathrm{~m}, 2 \mathrm{H}, \mathrm{CH}_{2}\right), 4.89-4.93$ (m, $1 \mathrm{H}$, oxazole- $\mathrm{CH}), 7.11-7.34$ (m, 5H, Ar-H), 7.62-7.64 (m, 1H, Ar-H), 7.86-7.94 (m, 2H, Ar-H), 7.95 (s, 1H, C=CH), 8.29-8.31 (m, $1 \mathrm{H}, \mathrm{Ar}-\mathrm{H}) ;{ }^{13} \mathrm{C}$ NMR $\left(100 \mathrm{MHz}\right.$, DMSO- $\left.d_{6}\right)$ $\delta 176.8,166.8,164.9,163.3,162.4,159.6,155.5,140.5$, $133.0,131.5,129.8,128.9,127.9,127.8,126.8,125.7$, 125.6, 105.6, 62.4, 53.1, 51,9, 51.7, 44.6, 38.5, 35.3, 29.4, 28.2; IR (KBr) $v_{\max } / \mathrm{cm}^{-1}: 2949,1720,1652$.

Methyl 2-(3-((3-(2-hydroxyphenyl)-4,5-dihydroisoxazol-5-yl)methyl)-4-oxo-3,4-dihydrophthalazin-1-yl)3-methoxyacrylate (7l). Yield 46\%; Purity 97.6\%; White solid; mp 144.9-146. ${ }^{\circ} \mathrm{C}$. MS (ESI) $\mathrm{m} / z: 436.1(\mathrm{M}+\mathrm{H})^{+}$; ${ }^{1} \mathrm{H}$ NMR (400 MHz, DMSO- $\left.d_{6}\right) \delta 3.31-3.55\left(2 \mathrm{~m}, 2 \mathrm{H}, \mathrm{CH}_{2}\right)$, $3.61\left(\mathrm{~s}, 3 \mathrm{H}, \mathrm{CH}_{3}\right), 3.84\left(\mathrm{~s}, 3 \mathrm{H}, \mathrm{CH}_{3}\right), 4.16-4.50(2 \mathrm{~m}, 2 \mathrm{H}$, $\mathrm{CH}_{2}$ ), 5.09-5.13 (m, 1H, oxazole- $\left.\mathrm{CH}\right), 6.89-6.96(\mathrm{~m}, 2 \mathrm{H}$,
Ar-H), 7.29-7.34 (m, 1H, Ar-H), 7.42-7.45 (m, 1H, Ar-H), 7.62-7.64 (m, 1H, Ar-H), 7.86-7.94 (m, 3H. Ar-H), 7.95 (s, $1 \mathrm{H}, \mathrm{C}=\mathrm{CH}), 9.85$ (brs, $1 \mathrm{H}, \mathrm{OH}) ;{ }^{13} \mathrm{C}$ NMR $(400 \mathrm{MHz}$, DMSO- $\left.d_{6}\right) \delta 177.8,166.6,164.8,163.2,162.3,159.6$, 155.6, 140.4, 133.1, 131.4, 129.8, 128.8, 127.6, 126.2, 125.7, 125.1, 105.6, 78.4, 62.4, 53.3, 51.8, 38.2, 29.5; IR $(\mathrm{KBr}) \mathrm{v}_{\max } / \mathrm{cm}^{-1}: 3320,2950,1710,1657$.

\section{Antimicrobial assay}

All the synthesised 3-isoxazoline substituted phthalazine-methoxyacrylate compounds $\mathbf{7 ( a - l )}$ were evaluated for their in vitro antimicrobial activity against E.coli, S. aureus, B. subtilis, S. typhi, bacterial stains and A. niger, C. albicans, fungal strains by disc diffusion method. Amoxicillin and Ketoconazole were used as standard drugs for bacteria and fungi respectively. Preliminary screening of 3-isoxazoline substituted phthalazine-methoxyacrylates and standard drugs were performed at fixed concentrations of $500 \mu \mathrm{g} / \mathrm{mL}$. Inhibition was recorded by measuring the diameter of the inhibition zone at the end of $24 \mathrm{~h}$ for bacteria and $72 \mathrm{~h}$ for fungi. Each experiment was repeated twice.

Based on the results of zone of inhibition, the minimum inhibitory concentration (MIC) of compounds (7a-l) against all bacterial and fungal strains was determined by liquid dilution method. Stock solutions of tested compounds with $200,100,50,25,12.5$ and $6.25 \mu \mathrm{g} \mathrm{mL}^{-1}$ concentrations were prepared with DMSO solvent. The solutions of standard drugs, Amoxicillin and Ketoconazole were prepared in the same concentrations. Inoculums of the bacterial and fungal culture were also prepared. To a series of tubes containing $1 \mathrm{~mL}$ each of phthalazine compound solution with different concentrations and $0.2 \mathrm{~mL}$ of the inoculums was added. Further $3.8 \mathrm{~mL}$ of the sterile water was added to each of the test tubes. These test tubes were incubated for $24 \mathrm{~h}$ at $37^{\circ} \mathrm{C}$ and observed for the presence of turbidity. This method was repeated by changing phthalazine compounds with standard drugs Amoxicillin and Ketoconazole for comparison. The minimum inhibitory concentration at which no growth was observed was taken as the MIC values (Table 1). The comparison of the MICs (in $\mu \mathrm{g} / \mathrm{mL}$ ) of potent compounds and standard drugs against tested strains are presented in Table 1.

\section{In-vitro Cytotoxicity Assay Using Calu-6 Cells}

Materials. MTT reagent, $\mathrm{CO}_{2}$ incubator, plate reader, Calu-6 cell line, 96 well plate, and solubilization solution.

Method. In vitro cytotoxicity assay was carried out at G7 Synergon Pvt. Ltd., Bangalore-560 092, India. The Calu-6 cells were initially purchased from ATCC at passage no.16 were grown in MEM with 10\% FBS. The 70-80\% confluent 
Table 1. Antimicrobial activity of compounds 7(a-l)

\begin{tabular}{|c|c|c|c|c|c|c|}
\hline \multirow[t]{3}{*}{ Compounds } & \multicolumn{6}{|c|}{ Minimum inhibitory concentration (MIC) in $\mu \mathrm{g} / \mathrm{mL}$} \\
\hline & \multicolumn{4}{|c|}{ Bacterial strains } & \multicolumn{2}{|c|}{ Fungal strains } \\
\hline & S. aureus & B. subtilis & S. typhi & E. coli & A. niger & C. albicans \\
\hline $7 \mathbf{a}$ & 25 & 200 & 50 & 100 & 250 & 500 \\
\hline $7 \mathrm{~b}$ & 25 & 50 & 50 & 50 & 125 & 125 \\
\hline $7 \mathrm{c}$ & 25 & 50 & 50 & 50 & 62.5 & 62.5 \\
\hline $7 d$ & 50 & 100 & 50 & 100 & 62.5 & 62.5 \\
\hline $7 e$ & 12.5 & 12.5 & 12.5 & 25 & 125 & 250 \\
\hline $7 f$ & 50 & 50 & 100 & 50 & 250 & 250 \\
\hline $7 \mathrm{~g}$ & 200 & 200 & 100 & 100 & 62.5 & 125 \\
\hline $7 \mathrm{~h}$ & 12.5 & 12.5 & 25 & 12.5 & 31.25 & 31.25 \\
\hline $7 \mathbf{i}$ & 50 & 100 & 100 & 100 & 125 & 125 \\
\hline $7 \mathbf{j}$ & 50 & 50 & 100 & 50 & 250 & 125 \\
\hline $7 \mathrm{k}$ & 25 & 50 & 50 & 25 & 125 & 250 \\
\hline 71 & 25 & 25 & 50 & 100 & 250 & 250 \\
\hline Amoxicillin & 6.25 & 6.25 & 6.25 & 6.25 & - & - \\
\hline Ketaconazole & - & - & - & - & 31.25 & 31.25 \\
\hline
\end{tabular}

cells were trypsinized, centrifuged and seeded in a 96 well plate $\left(50,000\right.$ cells/well). The cells were incubated at $37^{\circ} \mathrm{C}$ for overnight. The confluent cells were washed with HBSS buffer \& further incubation with $50 \mu \mathrm{M}$ concentration of the compounds $7 \mathrm{a}-1$ for $24 \mathrm{~h}$ at $37{ }^{\circ} \mathrm{C}$. After $24 \mathrm{~h}$ incubation, the MTT reagent $(15 \mu \mathrm{L} /$ well) was added and incubated for $4 \mathrm{~h}$ at $37^{\circ} \mathrm{C}$. Following this, stop solution was added and incubated for $1 \mathrm{~h}$, mixed using multi channel pipette. Measured the absorbance at $570 \mathrm{~nm}$ in Tecan plate reader

Table 2. Cytotoxicity assay for compounds $7(\mathbf{a}-\mathbf{I})$ on Calu- 6 cells

\begin{tabular}{lcc}
\hline Compounds & $\begin{array}{c}\text { Average OD at } \\
570 \mathrm{~nm} \pm \text { SD }\end{array}$ & Viability \% \\
\hline Control & $1.96 \pm 0.11$ & 100 \\
Vehicle control (1\% DMSO) & $1.71 \pm 0.16$ & 100 \\
$\mathbf{7 a}$ & $1.78 \pm 0.06$ & 104 \\
$\mathbf{7 b}$ & $1.84 \pm 0.16$ & 108 \\
$\mathbf{7 c}$ & $1.70 \pm 0.25$ & 99 \\
$\mathbf{7 d}$ & $1.92 \pm 0.18$ & 113 \\
$\mathbf{7 e}$ & $1.93 \pm 0.04$ & 115 \\
$\mathbf{7 f}$ & $1.58 \pm 0.09$ & 92 \\
$\mathbf{7 g}$ & $1.82 \pm 0.04$ & 107 \\
$\mathbf{7 h}$ & $1.73 \pm 0.05$ & 101 \\
$\mathbf{7 i}$ & $1.69 \pm 0.12$ & 117 \\
$\mathbf{7 j}$ & $1.41 \pm 0.06$ & 102 \\
$\mathbf{7 k}$ & $1.68 \pm 0.08$ & 102 \\
$\mathbf{7 1}$ & $1.60 \pm 0.18$ & 99 \\
\hline
\end{tabular}

and repeated the entire experiment twice and the \pm SD was calculated and reported in Table 2.

\section{Supplementary Information}

Supplementary information (Figure S1-S24) is available free of charge at http://jbcs.sbq.org.br as a PDF file.

\section{Acknowledgments}

The author A. M. Sridhara is thankful to Advinus Therapeutics Pvt. Ltd. Bangalore, Chairman, Department of Industrial Chemistry, Kuvempu University, Dr. Yogisha, Director, G7 Synergon, Bangalore, Karnataka, India for supporting the research.

\section{References}

1. Bartlett, D. W.; Clough, J. M.; Godwin, J. R.; Hall, A. A.; Hamer, M.; Parr- Dobrzanski, B.; Pest Manag. Sci. 2002, 58, 649.

2. Sauter, H.; Steglich, W.; Anke, T.; Angew. Chem., Int. Ed. 1999, 38, 1328.

3. Milata, V.; Acta Chim. Slov. 2008, 1, 221.

4. Beautement, K.; Clough, J. M.; De Fraine, P. J.; Godfrey, C. R. A.; Pestic. Sci. 1991, 21, 499.

5. Chen, H.; Taylor, J. L.; Abrams, S. R.; Bioorg. Med. Chem. Lett. 2007, 17, 1979.

6. Alzeer, J.; Chollet, J.; Heinze-Krauss, I.; Hubschwerlen, C.; Matile, H.; Ridley, R. G.; J. Med. Chem. 2000, 43, 560. 
7. Balba, H.; J. Environ. Sci. Health, Part B 2007, 42, 441.

8. Smith, K.; Evans, D. A.; El-Hiti, G. A.; Phil. Trans. R. Soc. B 2008, 363, 623 .

9. Liu, A.; Wang, X.; Ou, X.; Huang, M.; Chen, C.; Liu, S.; Huang, L.; Liu, X.; Zhang, C.; Zheng, Y.; Ren, Y.; He, L.; Yao, J.; J. Agric. Food Chem. 2008, 56, 6562.

10. Boland, O. M.; Blackwell, C. C.; Clarke, B. F.; Ewing, D. J.; Diabetes 1993, 42, 336.

11. Hamamoto, Y.; Nagai, K.; Muto, M.; Asagami, C.; Exp. Dermatol. 1993, 2, 231.

12. Del Olmo, E.; Barboza, B.; Ybarra, M. I.; Lopez-Perez, J. L.; Carron, R.; Sevilla, M. A.; Boselli, C.; San Feliciano, A.; Bioorg. Med. Chem. Lett. 2006, 16, 2786.

13. Napoletano, M.; Norcini, G.; Pellacini, F.; Marchini, F.; Morazzoni, G.; Ferlenga, P.; Pradella, L.; Bioorg. Med. Chem. Lett. 2000, 10, 2235.

14. Bold, G.; Altmann, K. H.; Frei, J.; Lang, M.; Manley, P. W.; Traxler, P.; Wietfeld, B.; Brueggen, J.; Buchdunger, E.; Cozens, R.; Ferrari, S.; Furet, P.; Hofmann, F.; Martiny-Baron, G.; Mestan, J.; Roesel, J.; Sills, M.; Stover, D.; Acemoglu, F.; Boss, E.; Emmenegger, R.; Laesser, L.; Masso, E.; Roth, R.; Schlachter, C.; Vetterli, W.; Wyss, D.; Wood, J. M.; J. Med. Chem. 2000, 43, 2310

15. Yamaguchi, M.; Kamei, K.; Koga, T.; Akima, M.; Maruyama, A.; Kuroki, T.; Ohi, N.; J. Med. Chem. 1993, 36, 4061.

16. Li, Y. X.; Luo, Y. P.; Xi, Z.; Niu, C. W.; He, Y. Z.; Yang, G. F.; J. Agric. Food Chem. 2006, 54, 9135.

17. Leenen, F. H. H.; Smith, D. L.; Faraks, R. M.; Reeves, R. A.; Marquez-Julio, A.; Am. J. Med. 1987, 82, 969.

18. Leiro, J. M.; Alvarez, E.; Arranz, J. A.; Cano, E.; Orallo, F.; Int. Immunopharmacol. 2004, 4, 163.

19. Tanaka, S.; Tanaka, M.; Akashi, A.; Stroke 1989, 20, 1724.

20. Moroi, R.; Ono, K.; Saito, T.; Akimoto, T.; Sano, M.; Chem. Pharm. Bull. 1977, 25, 830.
21. Kemp, J. P.; Meltzer, E. O.; Orgel, H. A.; Welch, M. J.; Bucholtz, G. A.; Middleton, E.; Spector, S. L.; Newton, J. J.; Perhach Jr, J. L.; J. Allergy Clin. Immunol. 1987, 79, 893.

22. Scheffler, G.; Engel, J.; Kutscher, B.; Sheldrick, W. S.; Bell, P.; Archiv. Pharm. 1988, 321, 205.

23. Kador, P. F.; Kinoshita, J. H.; Sharpless, N. E.; J. Med. Chem. 1985, 28, 841 .

24. Mylari, B. L.; Larson, E. R.; Beyer, T. A.; Zembrowski, W. J.; Aldinger, C. E.; Dee, M. F.; Siegel, T. W.; Singleton, D. H.; J. Med. Chem. 1991, 34, 108.

25. Kai, H.; Matsumoto, H.; Hattori, N.; Takase, A.; Fujiwara, T.; Sugimoto. H.; Bioorg. Med. Chem. Lett. 2001, 11, 1997.

26. Basappa, M. P.; Sadashiva, K.; Mantelingu, S.; Nanjunda Swamy.; Rangappa, K. S.; Bioorg. Med. Chem. 2003, 11, 4539.

27. Tangallapally, P. R.; Sun, D.; Nageshwar, B. R.; Lee, E. B. R.; Lenaerts, J. M. A.; Meibohm, B.; Lee, E. R.; Bioorg. Med. Chem. Lett. 2007, 17, 6638.

28. Srivastava, S.; Bajpai, L. K.; Batra, S.; Bhaduri, A. P.; Maikhuri, J. P.; Gupta, G.; Dhar, J. D.; Bioorg. Med. Chem. 1999, 7, 2607.

29. Conti, C.; Dallanoce, M. D.; Amici, C. D.; Micheli.; Klotz, K. N.; Bioorg. Med. Chem. 1998, 6, 401.

30. Habeeb, A. G.; Praveen Rao, P. N.; Knaus, E. E.; J. Med. Chem. 2001, 44, 2921.

31. Terry, G.; Sinay Jr.; Robert, J.; Sysko; U.S. Patent 4904782 , 1990.

32. Huisgen, R.; Angew. Chem., Int. Ed. Engl. 1963, 2, 565.

33. Liu, K. C.; Shelton, B. R.; Howe, R. K.; J. Org. Chem. 1980 , $45,3916$.

34. Meaney, C.; Florea, B. I.; Borchard, G.; Junginger, H. E.; AAPS PharmSci. 2002, 4, 1.

Submitted: August 26, 2010

Published online: February 1, 2011 


\section{Synthesis, Antimicrobial and Cytotoxicity Studies of Some Novel Modified Strobilurin Derivatives}

\section{Ajjanna M. Sridhara, ${ }^{a, b}$ Kallam R. Venugopala Reddy, ${ }^{*, b}$ Jathi Keshavayya, ${ }^{c}$ Dasannana Malige S. Ambika, ${ }^{e}$ Vadiraj S. Gopinath, ${ }^{a}$ Prosenjit Bose, ${ }^{a}$ Sanath Kumar Goud ${ }^{a}$ and Sanenahalli K. Peethambard}

${ }^{a}$ Advinus Therapeutics Pvt. Ltd, 21 \& 22, Peenya II phase, Bangalore-560 058, India

${ }^{b}$ Department of Studies in Industrial Chemistry, ${ }^{c}$ Department of Studies in Chemistry and ${ }^{d}$ Department of Biochemistry, Kuvempu University, Jnana Sahyadri, Shankaragatta-577 451,

Karnataka, India

${ }^{e}$ Department of Plant Pathology, G.K.V.K, UAS, Bangalore-65 India

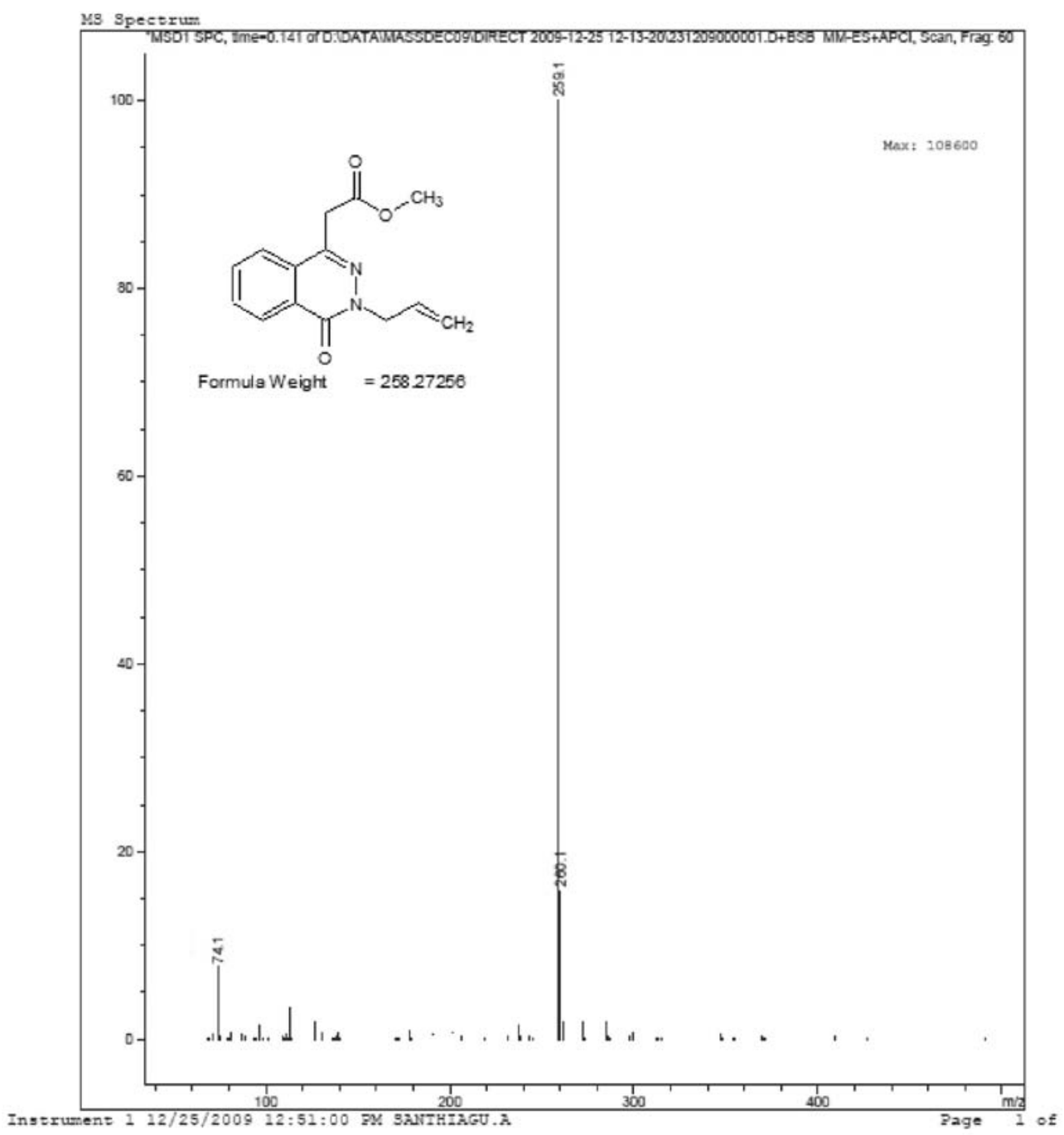

Figure S1. Mass spectrum of methyl 2-(3-allyl-4-oxo-3,4-dihydrophthalazin-1-yl)acetate (5).

*e-mail: venurashmi30@rediffmail.com 


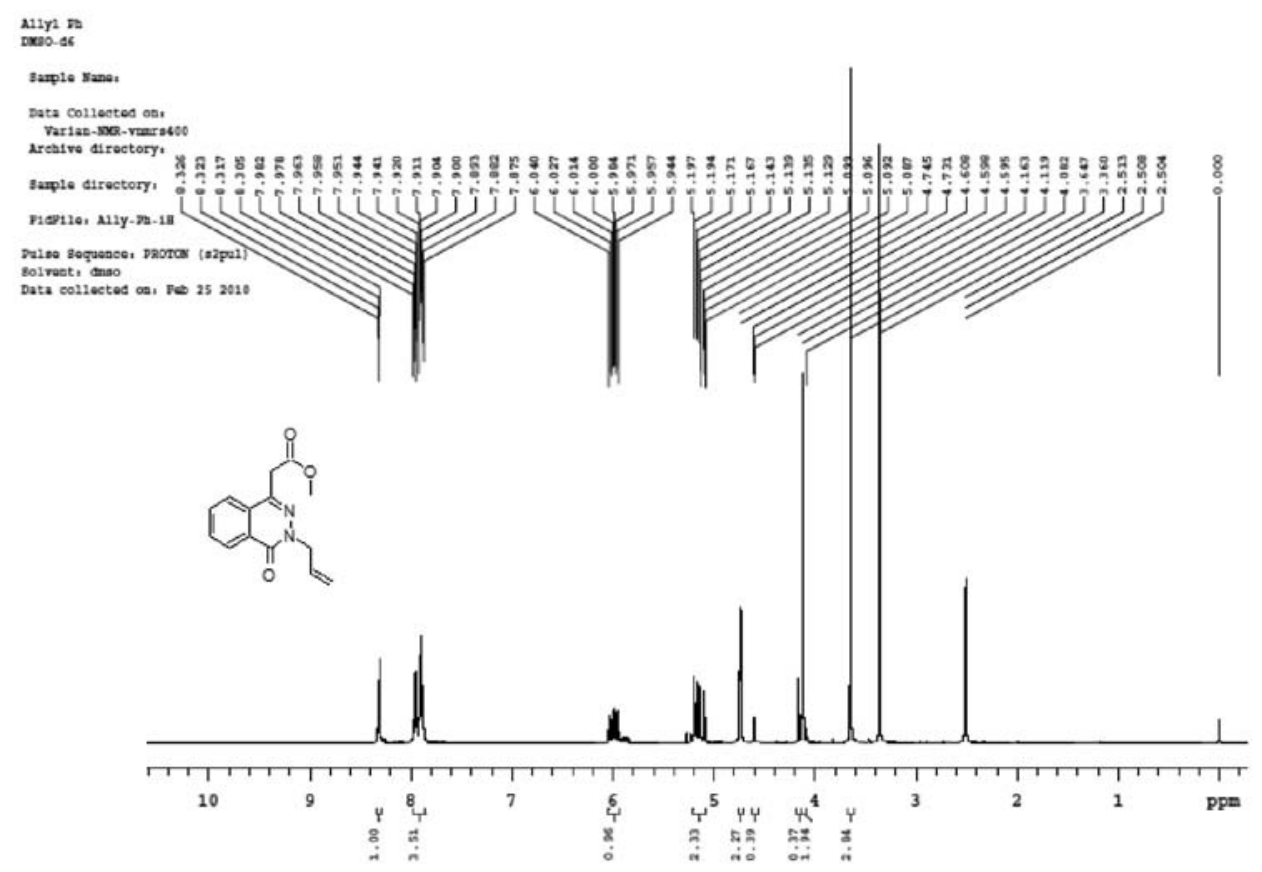

Figure S2. 'H NMR spectrum of methyl 2-(3-allyl-4-oxo-3,4-dihydrophthalazin-1-yl)acetate (5).

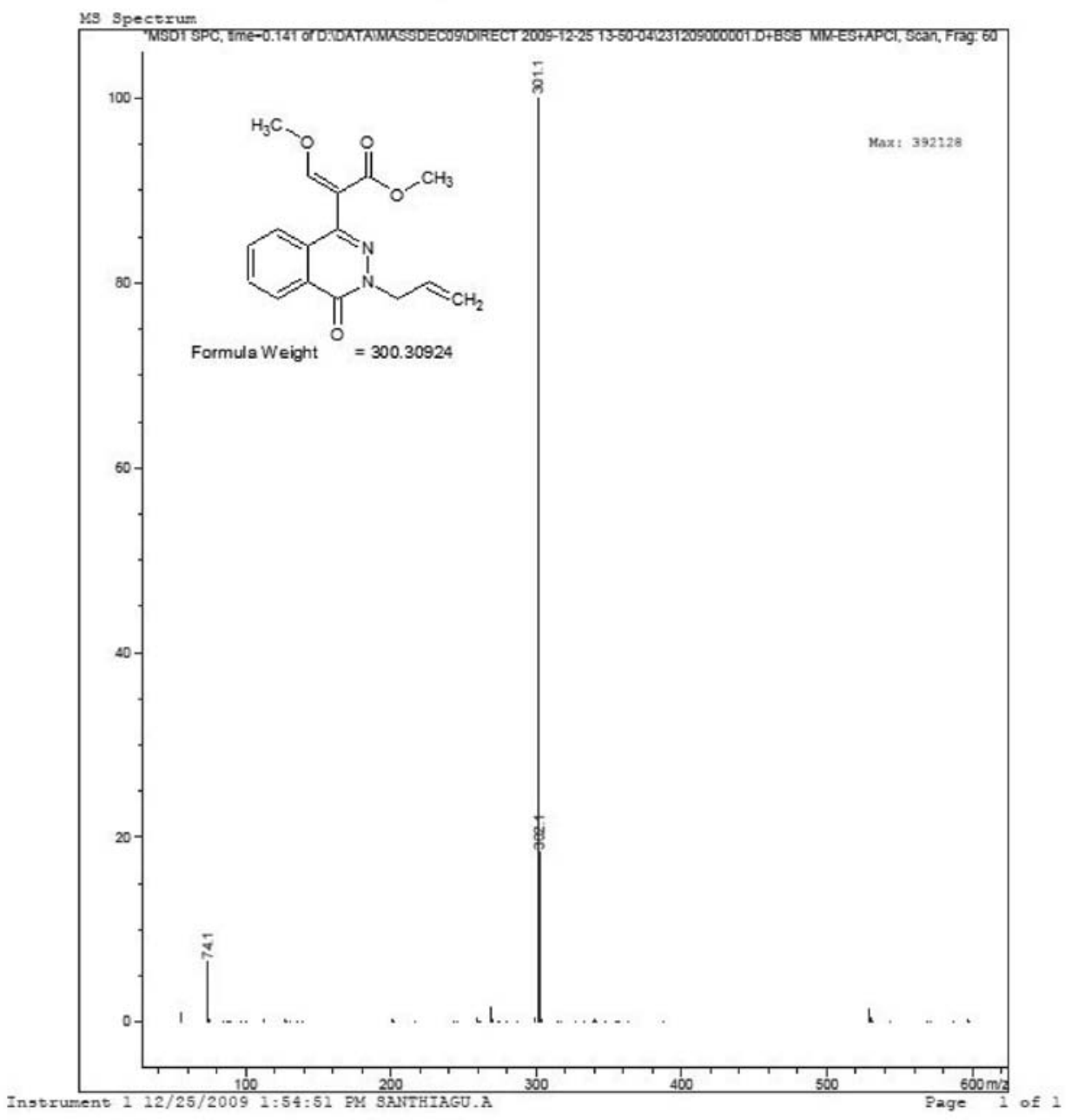

Figure S3. Mass spectrum of methyl 2-(3-allyl-4-oxo-3,4-dihydrophthalazin-1-yl)-3-methoxy acrylate (6). 


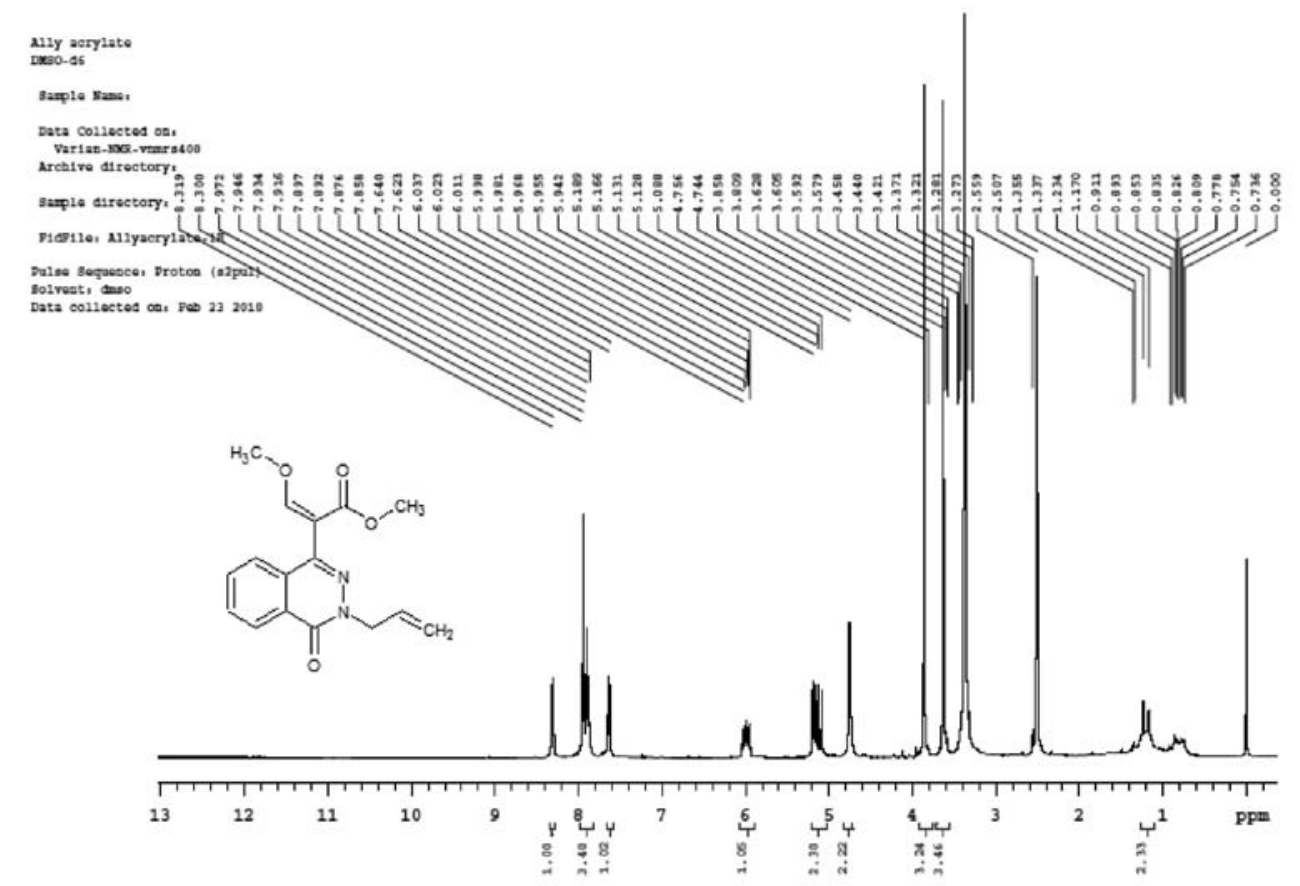

Figure S4. 'H NMR spectrum of methyl 2-(3-allyl-4-oxo-3,4-dihydrophthalazin-1-yl)-3-methoxy acrylate (6).

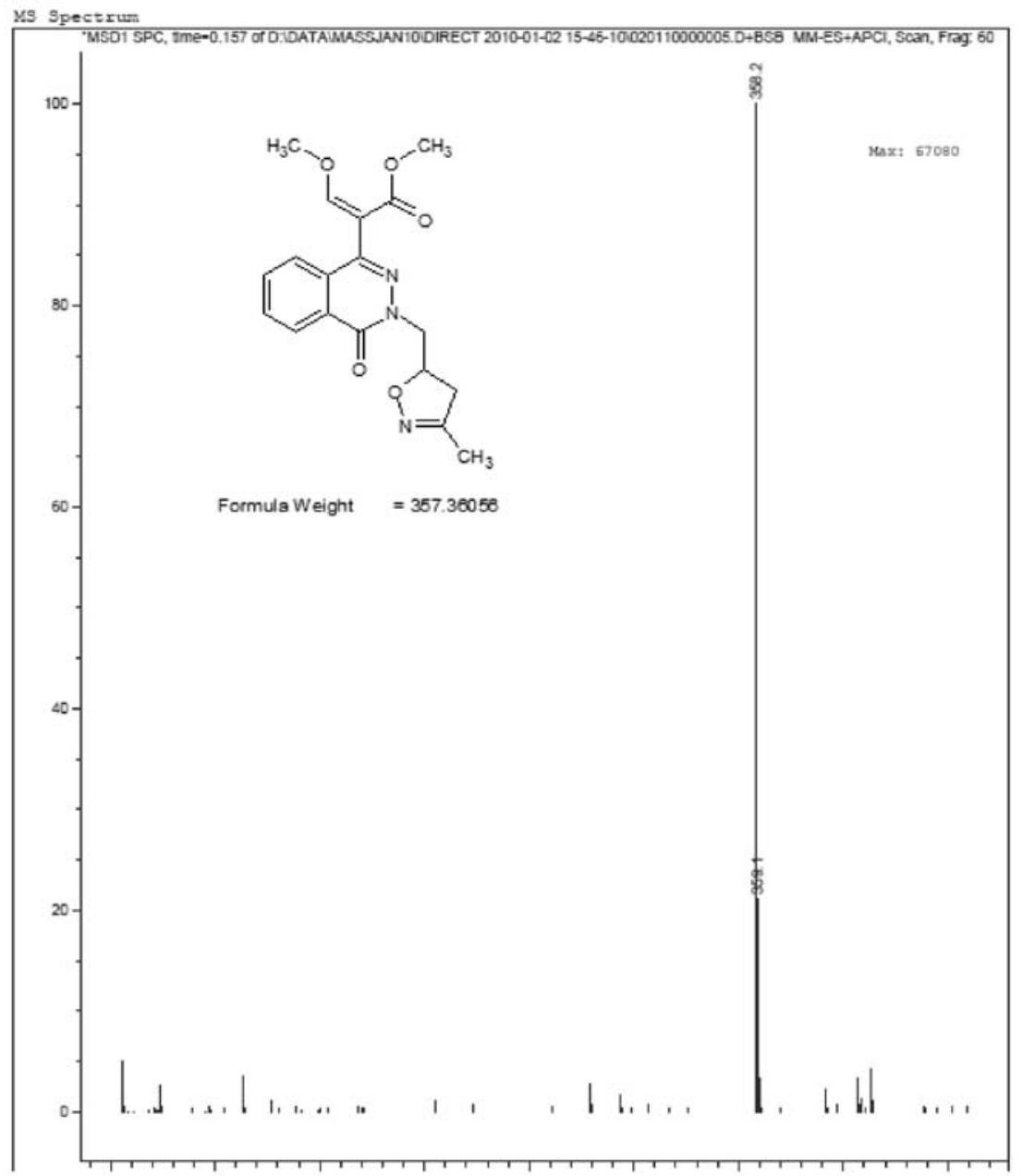

Figure S5. Mass spectrum of methyl 3-methoxy-2-(3-((3-methyl-4,5-dihydroisoxazol-5-yl)methyl)-4-oxo-3,4-dihydrophthalazin-1-yl)acrylate (7a). 


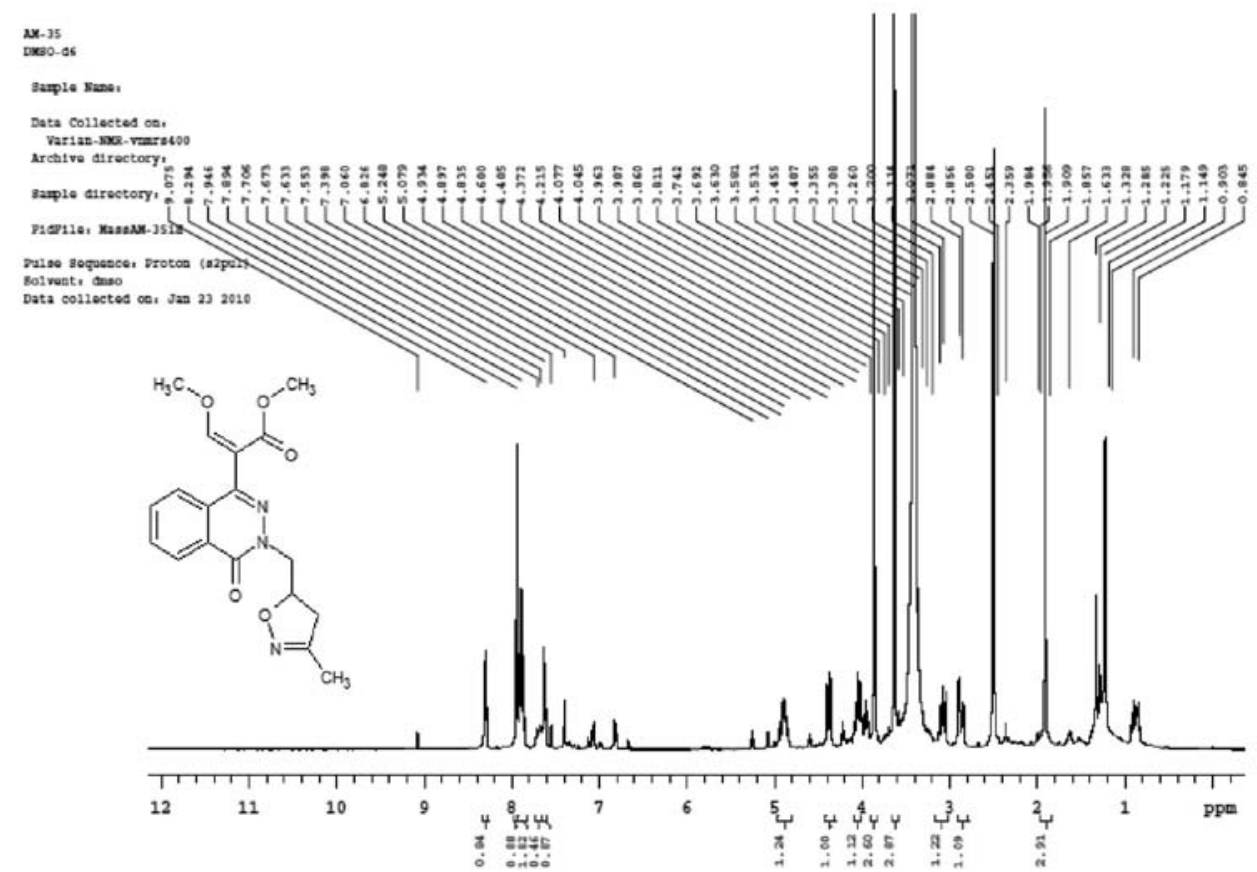

Figure S6. 'H NMR spectrum of methyl 3-methoxy-2-(3-((3-methyl-4,5-dihydroisoxazol-5-yl)methyl)-4-oxo-3,4-dihydrophthalazin-1-yl)acrylate (7a).

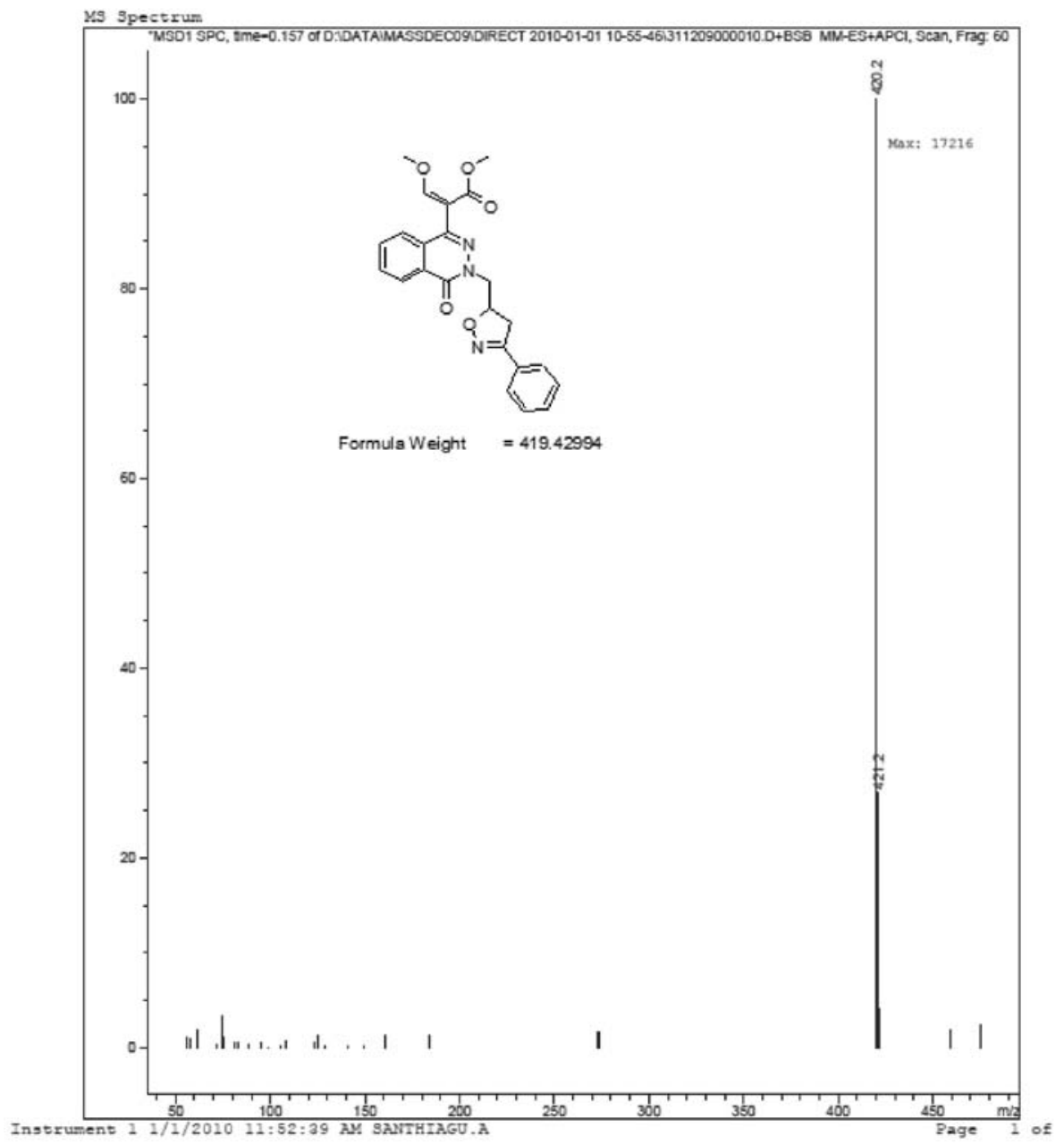

Figure S7. Mass spectrum of methyl 3-methoxy-2-(4-oxo-3-((3-phenyl-4,5-dihydroisoxazol-5-yl)methyl)-3,4-dihydrophthalazin-1-yl)acrylate (7b). 


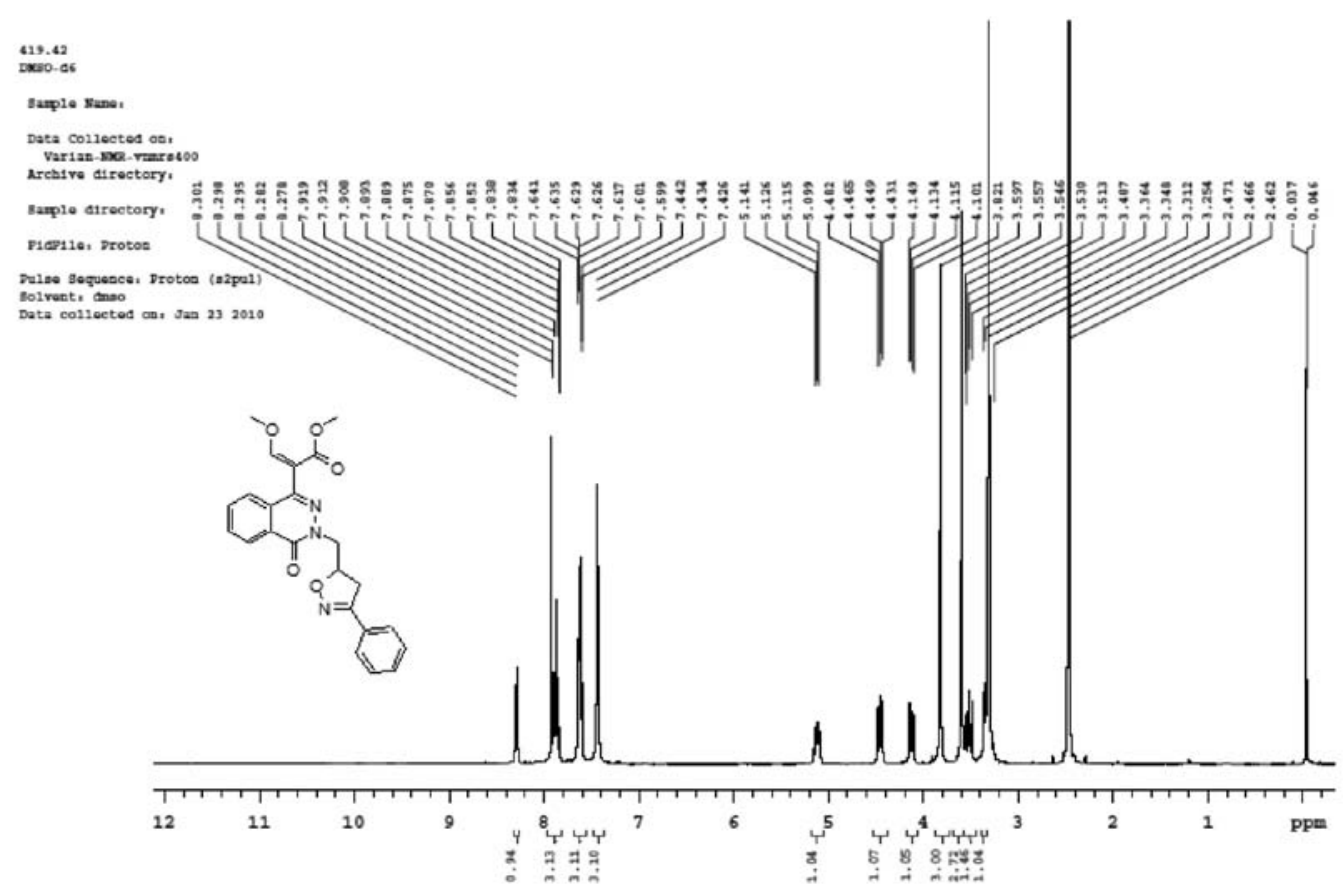

Figure S8. 'H NMR spectrum of methyl 3-methoxy-2-(4-oxo-3-((3-phenyl-4,5-dihydroisoxazol-5-yl)methyl)-3,4-dihydrophthalazin-1-yl)acrylate (7b).

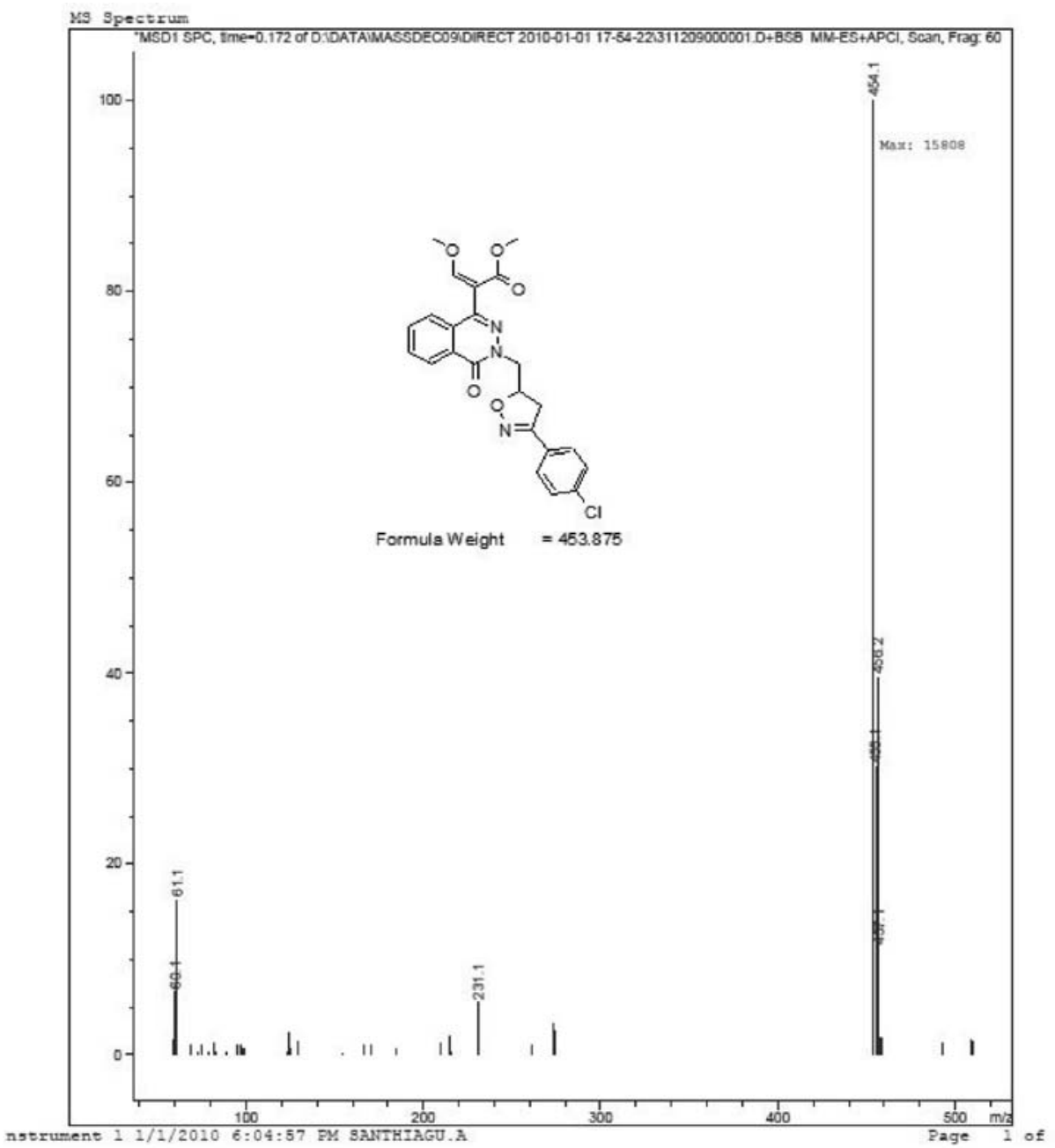

Figure S9. Mass spectrum of methyl 2-(3-((3-(4-chlorophenyl)-4,5-dihydroisoxazol-5-yl)methyl)-4-oxo-3,4-dihydrophthalazin-1-yl)-3-methoxyacrylate (7c). 


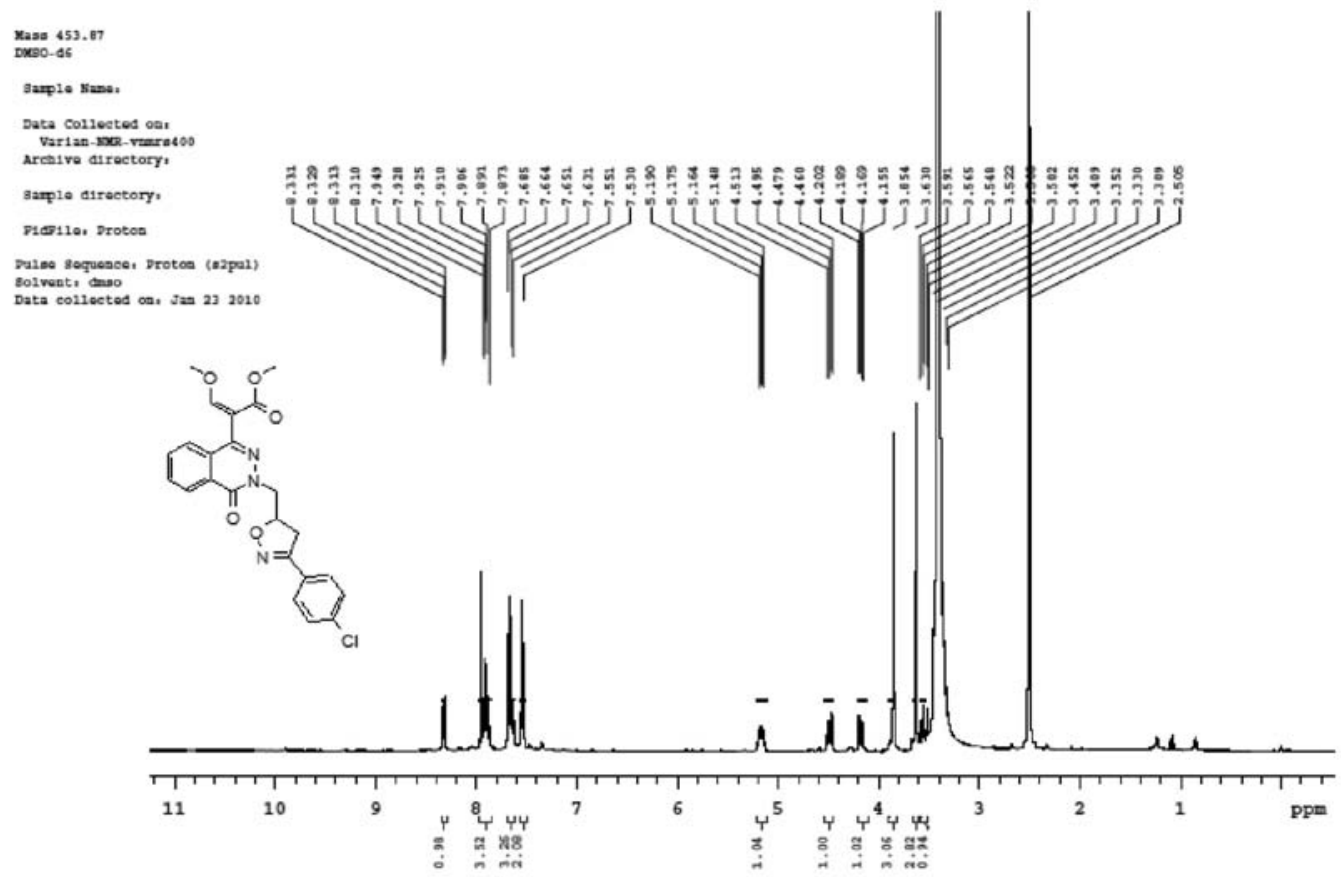

Figure S10. ${ }^{1} \mathrm{H}$ NMR spectrum of methyl2-(3-((3-(4-chlorophenyl)-4,5-dihydroisoxazol-5-yl)methyl)-4-oxo-3,4-dihydrophthalazin-1-yl)-3-methoxyacrylate (7c).

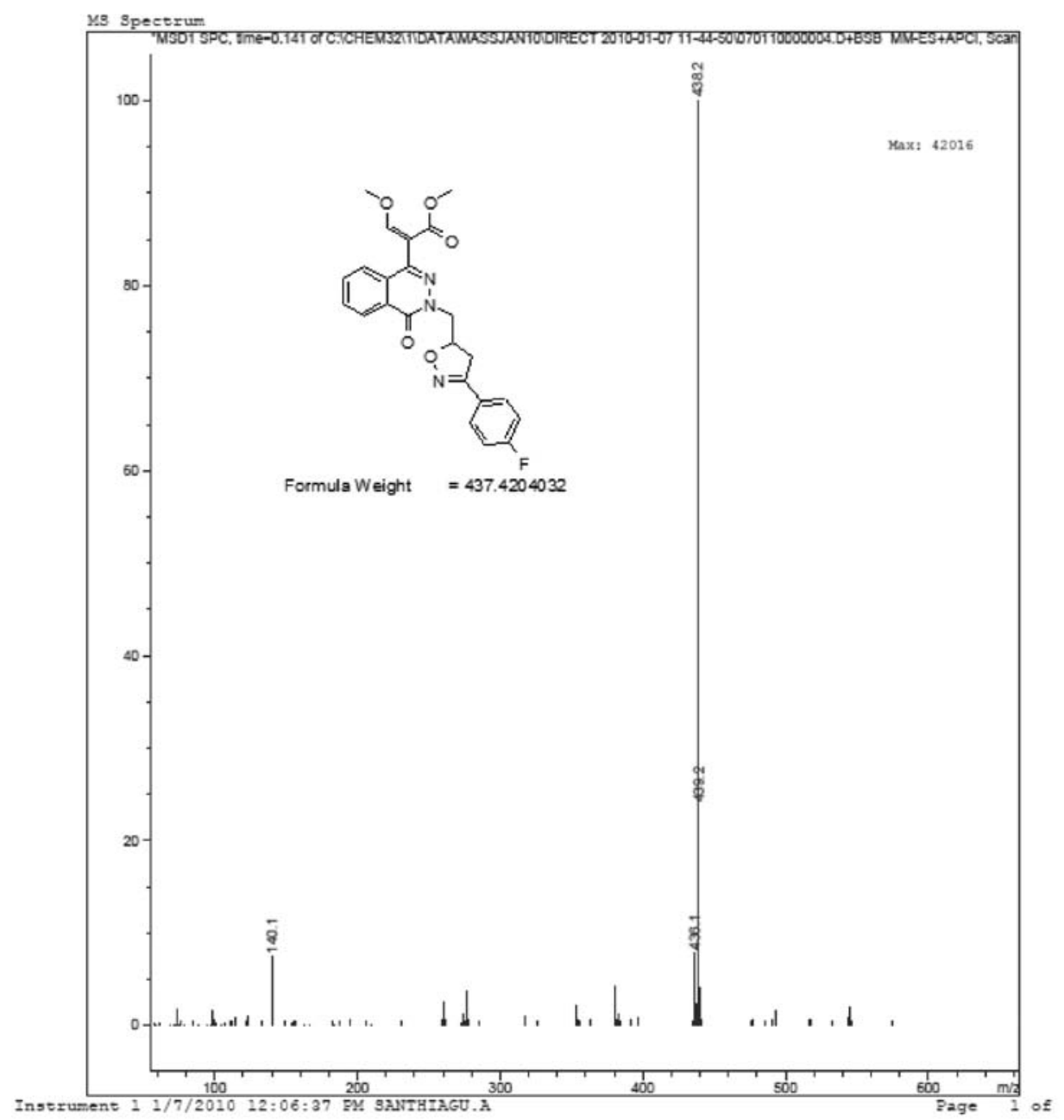

Figure S11. Mass spectrum of methyl 2-(3-((3-(4-fluorophenyl)-4,5-dihydroisoxazol-5-yl)methyl)-4-oxo-3,4-dihydrophthalazin-1-yl)-3-methoxyacrylate (7d). 

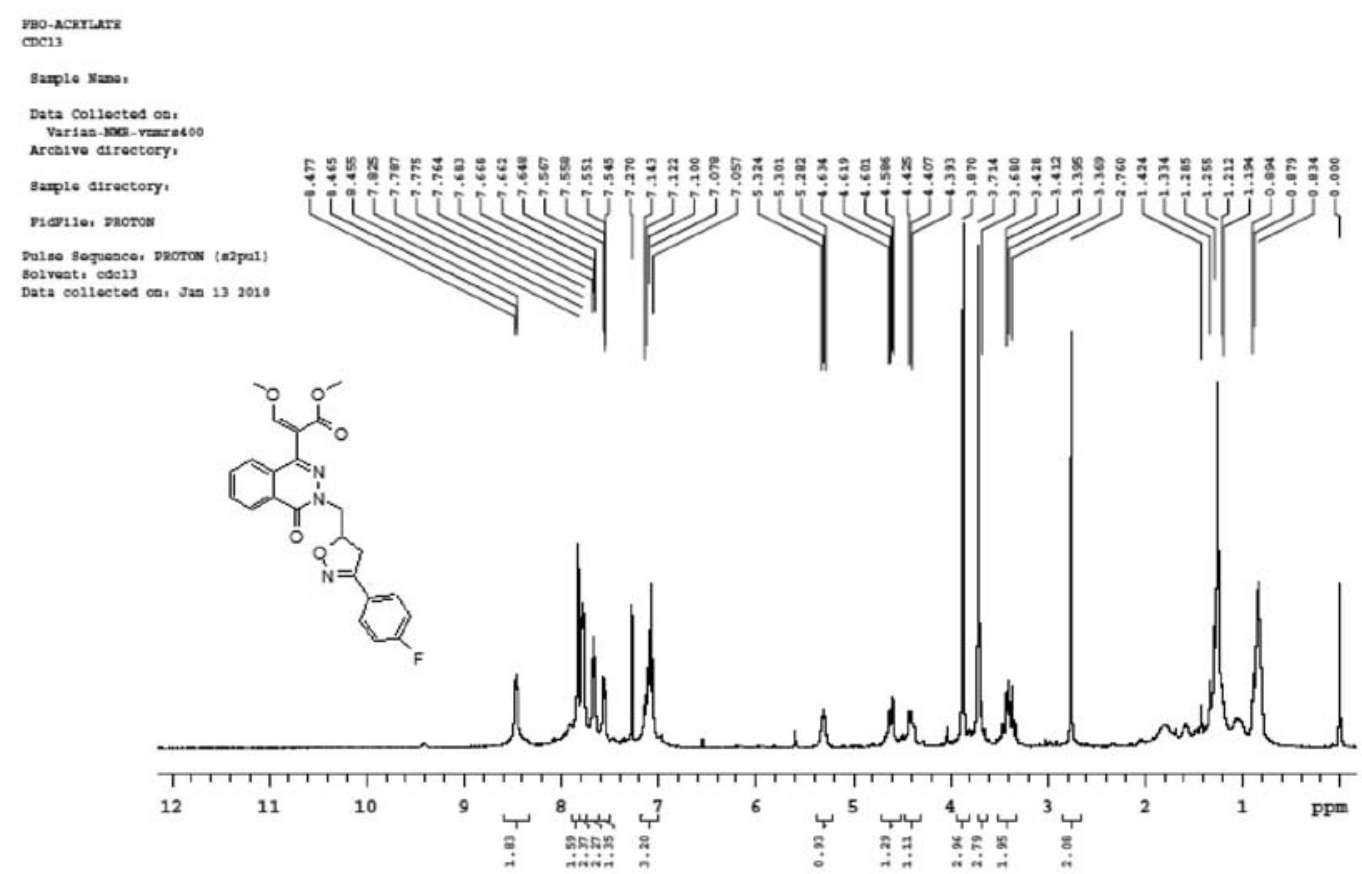

FigureS12. ${ }^{1} \mathrm{H}$ NMR spectrum of methyl 2-(3-((3-(4-fluorophenyl)-4,5-dihydroisoxazol-5-yl)methyl)-4-oxo-3,4-dihydrophthalazin-1-yl)-3-methoxyacrylate (7d).
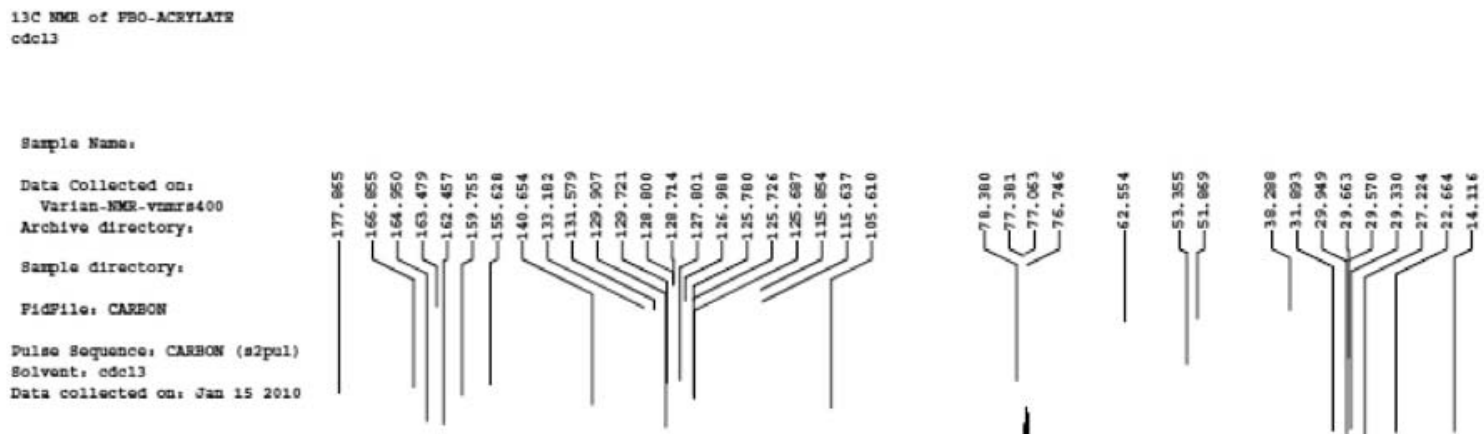<smiles>COC=C(C(=O)OC)c1nn(CC2CC(c3ccc(F)cc3)=NO2)c(=O)c2ccccc12</smiles>

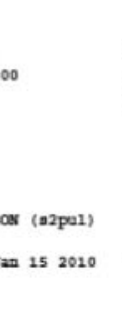

200

FigureS13. ${ }^{13} \mathrm{CNMR}$ spectrum of methyl2-(3-((3-(4-fluorophenyl)-4,5-dihydroisoxazol-5-yl)methyl)-4-oxo-3,4-dihydrophthalazin-1-yl)-3-methoxyacrylate (7d). 


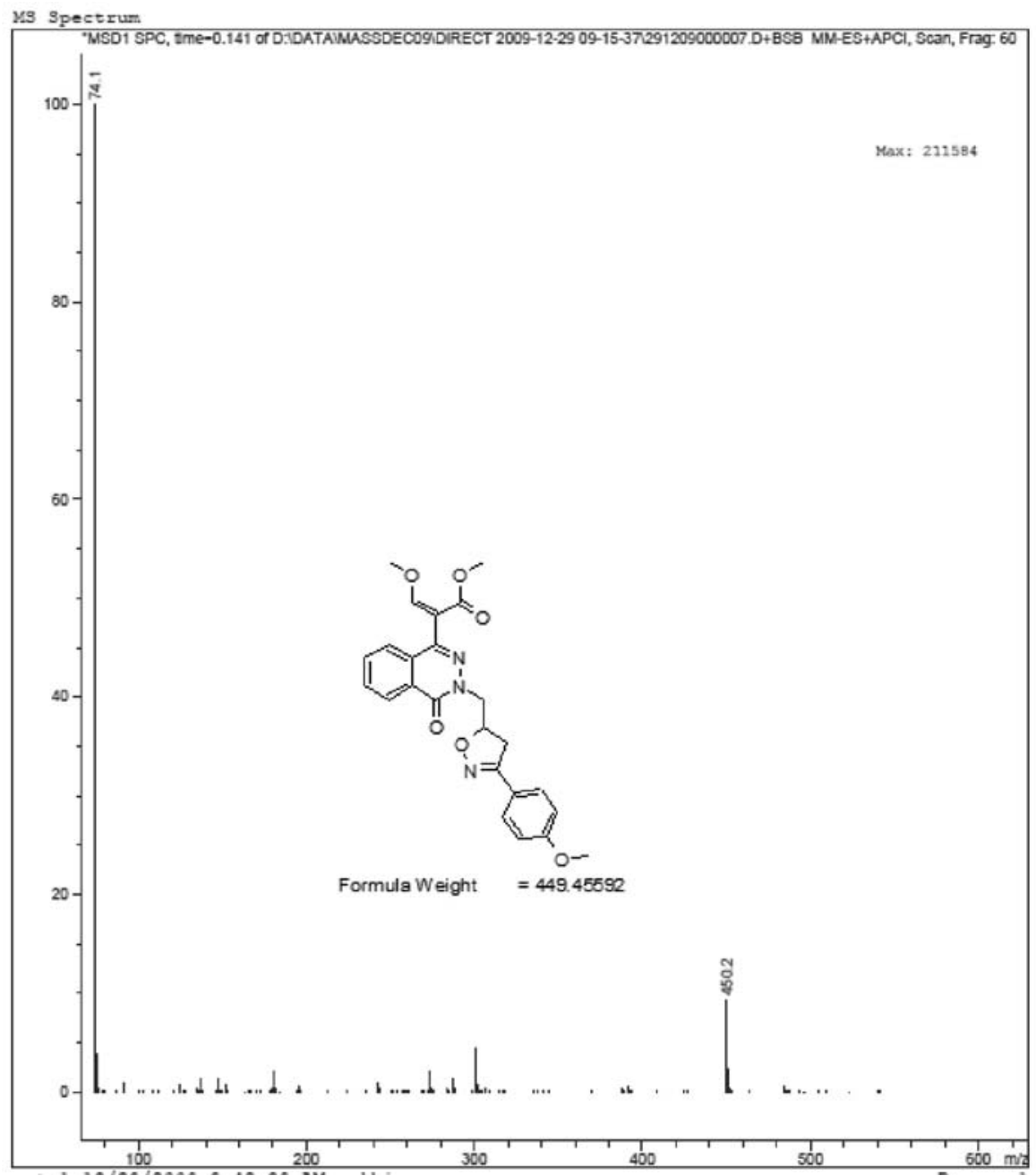

Figure S14. Mass spectrum of methyl 2-(3-((3-(3,4-dimethoxyphenyl)-4,5-dihydroisoxazol-5-yl)methyl)-4-oxo-3,4-dihydrophthalazin-1-yl)-3methoxyacrylate $(\mathbf{7 e})$.

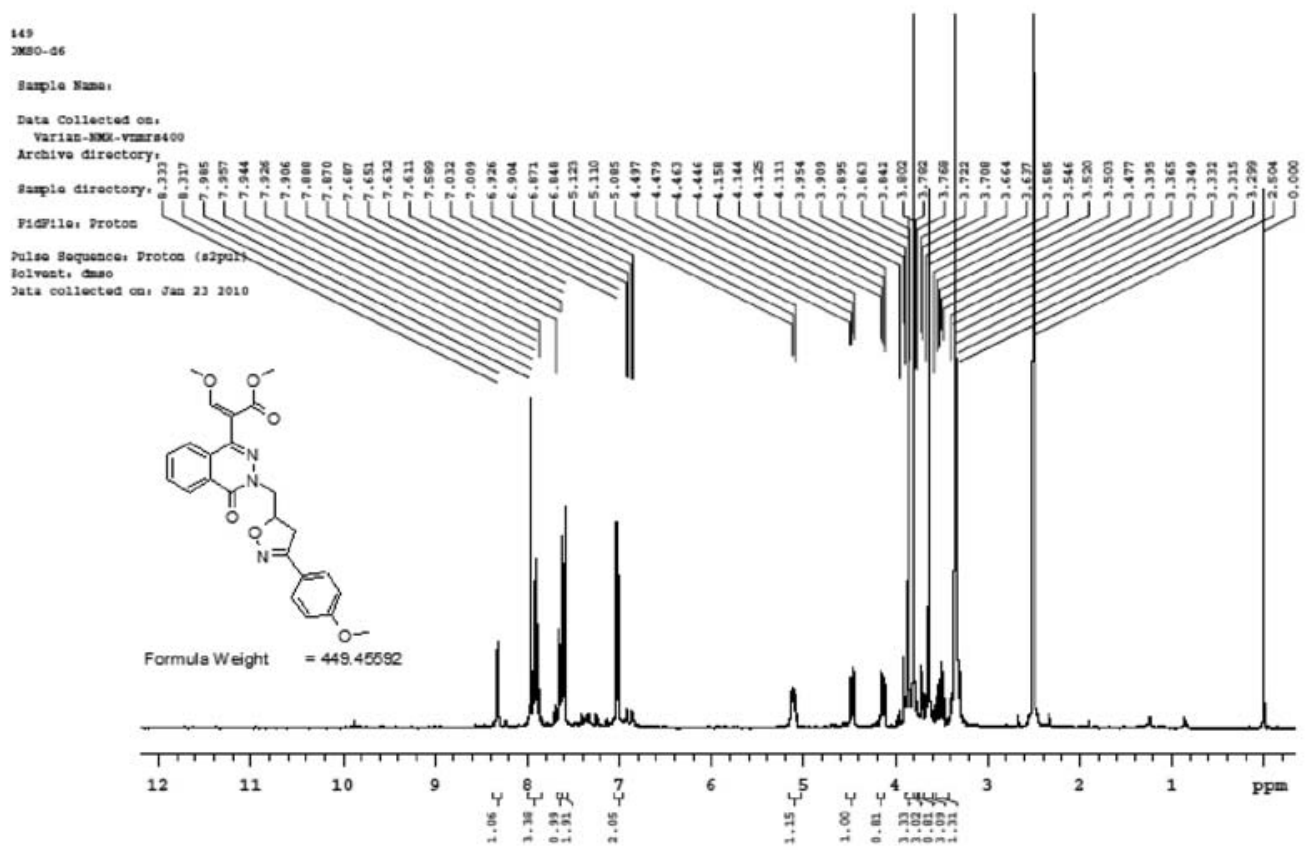

Figure S15. 'H NMR spectrum of methyl 2-(3-((3-(3,4-dimethoxyphenyl)-4,5-dihydroisoxazol-5-yl)methyl)-4-oxo-3,4-dihydrophthalazin-1-yl)-3methoxyacrylate (7e). 


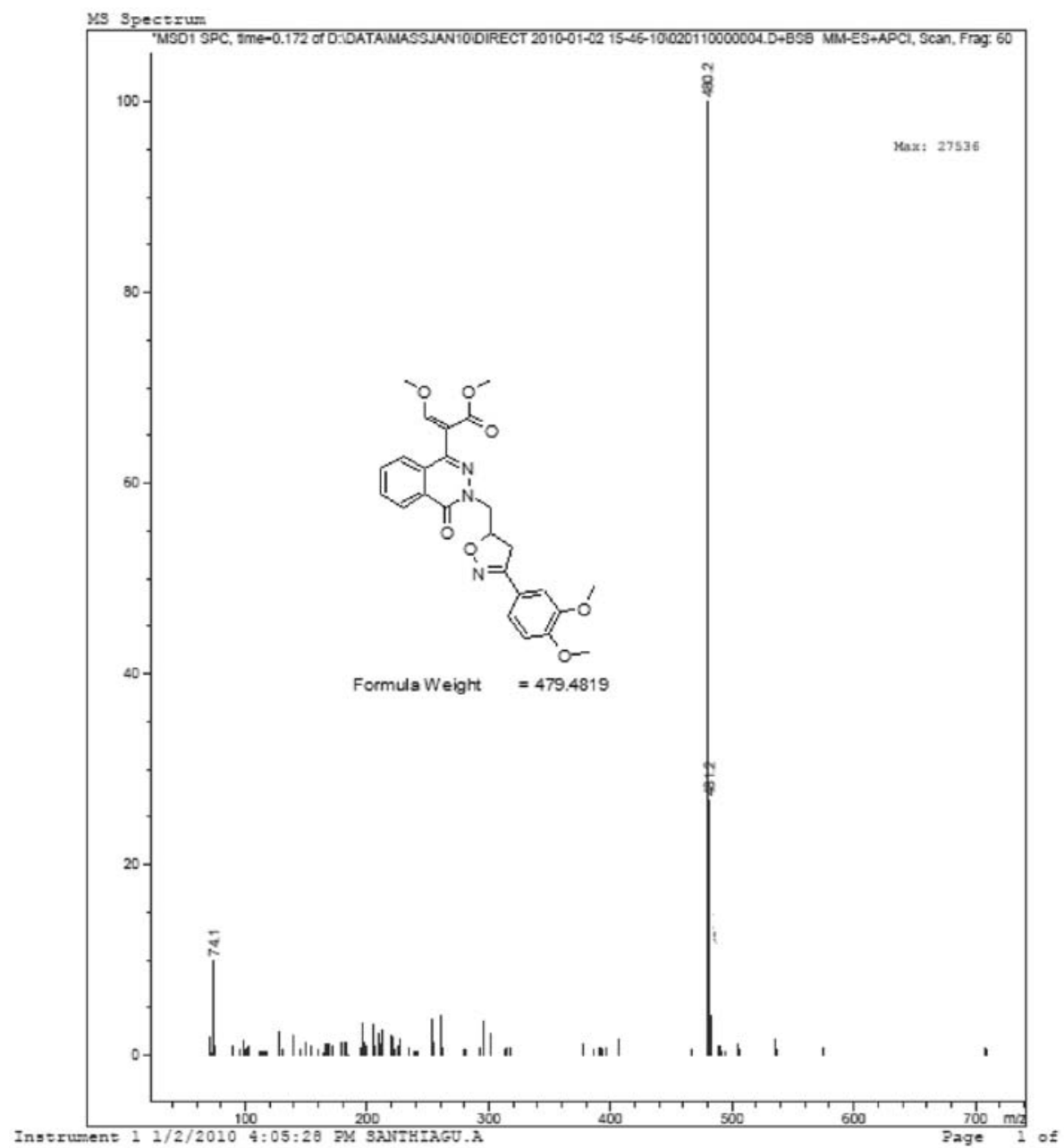

Figure S16. Mass spectrum of methyl 2-(3-((3-(3,4-dimethoxyphenyl)-4,5-dihydroisoxazol-5-yl)methyl)-4-oxo-3,4-dihydrophthalazin-1-yl)-3methoxyacrylate (7f).

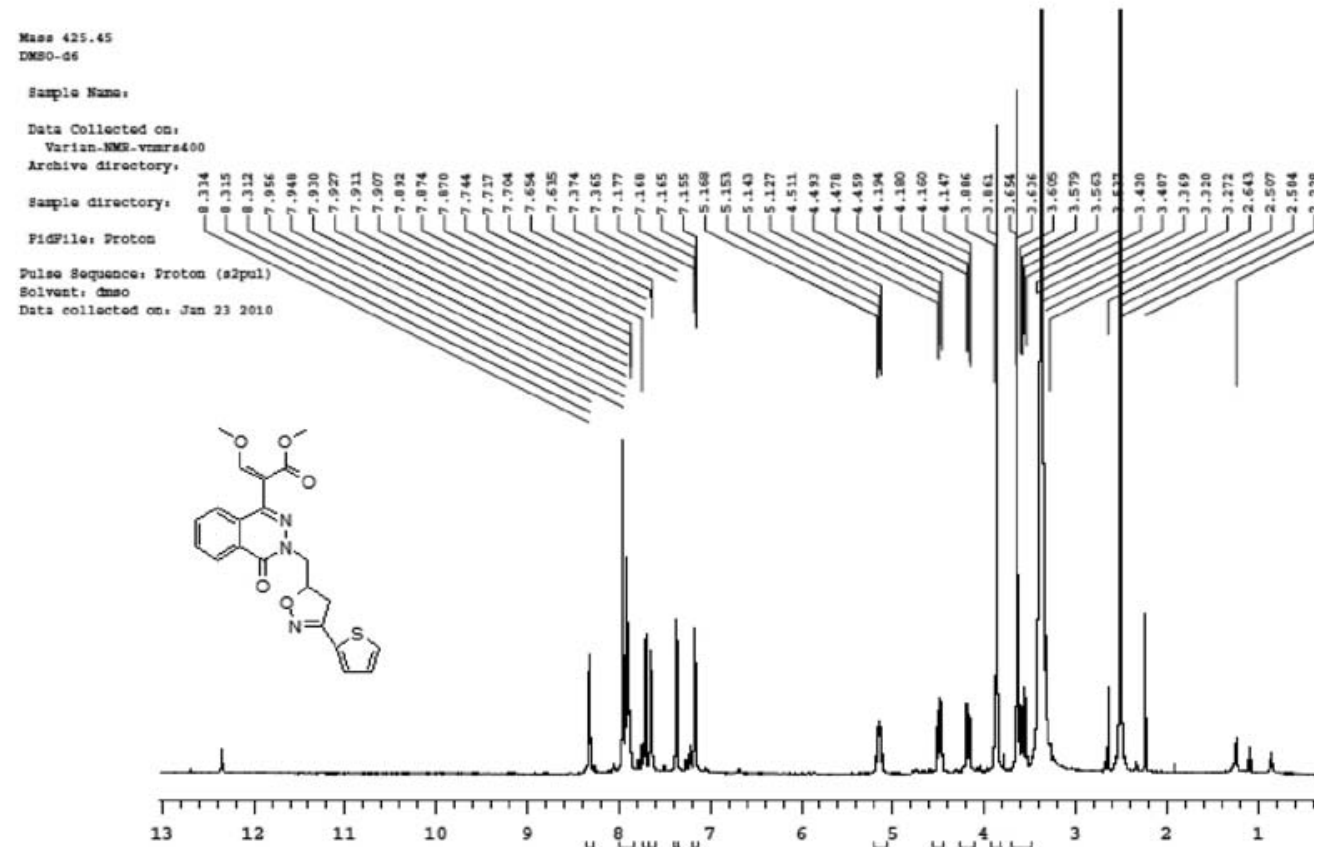

Figure S17. ${ }^{1} \mathrm{H}$ NMR spectrum of methyl 3-methoxy-2-(4-oxo-3-((3-(thiophen-2-yl)-4,5-dihydroisoxazol-5-yl) methyl)-3,4-dihydrophthalazin-1-yl) acrylate (7h). 


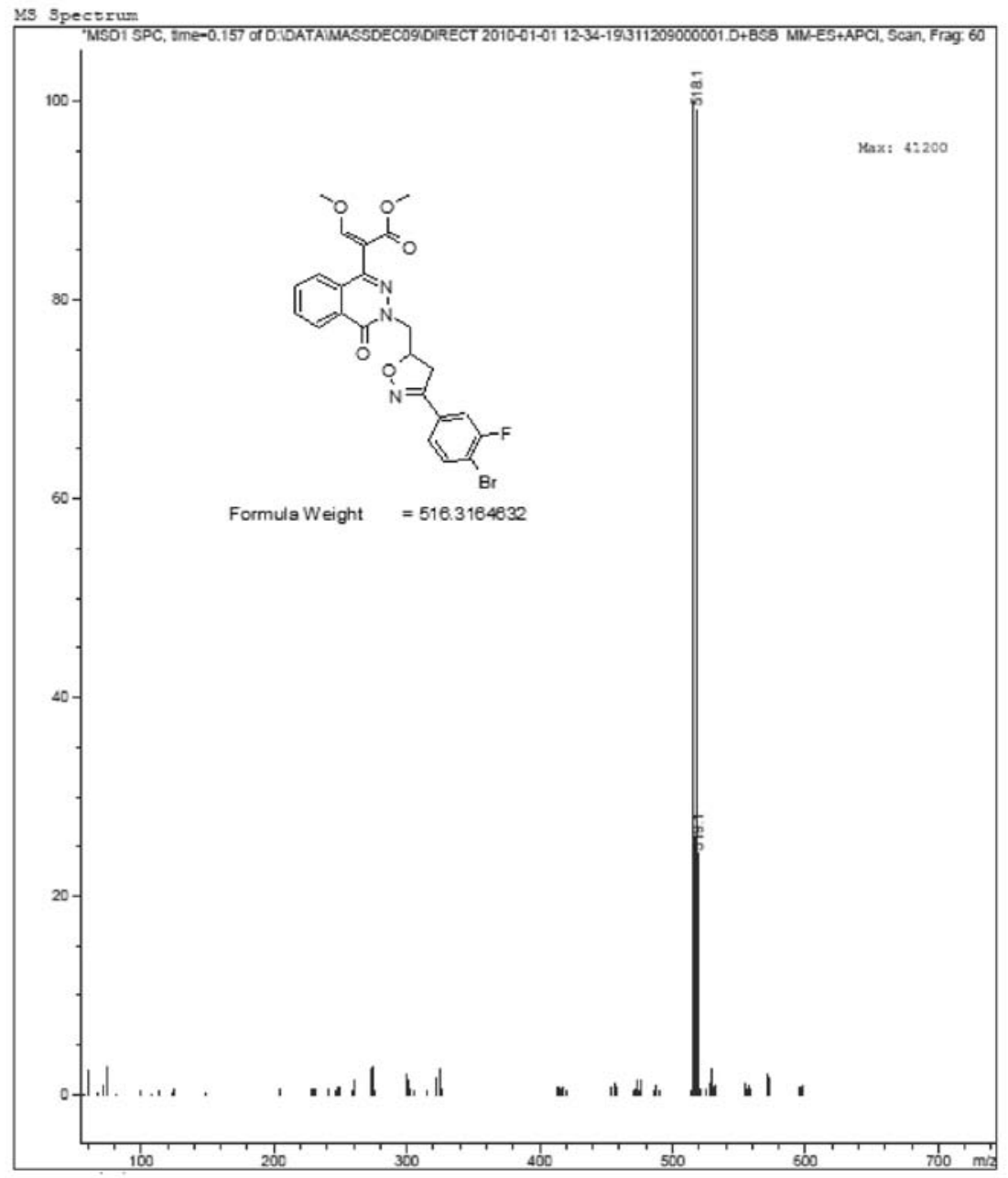

Figure S18. Mass spectrum of methyl 2-(3-((3-(4-bromo-3-fluorophenyl)-4,5-dihydroisoxazol-5-yl)methyl)-4-oxo-3,4-dihydrophthalazin-1-yl)-3methoxyacrylate (7i).
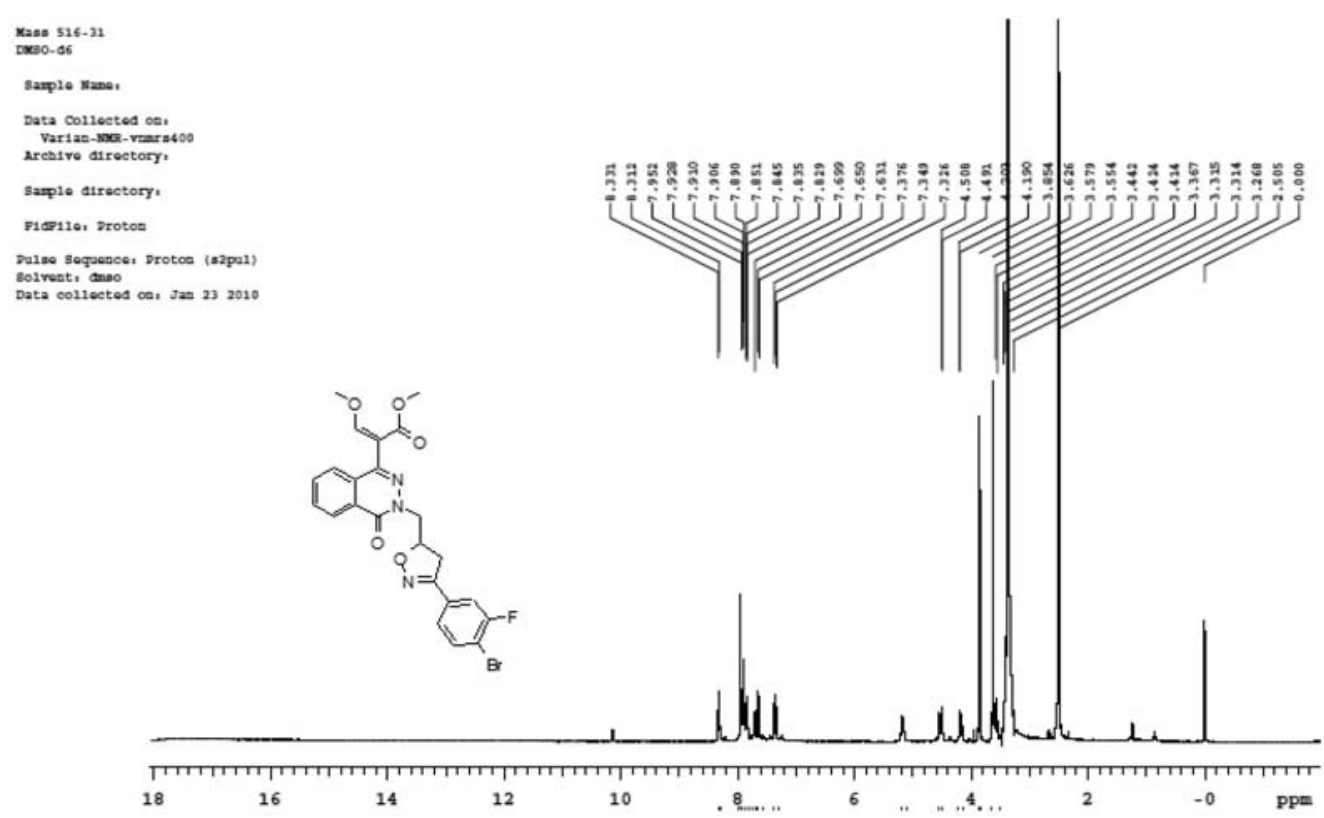

Figure S19. 'H NMR spectrum of methyl 2-(3-((3-(4-bromo-3-fluorophenyl)-4,5-dihydroisoxazol-5-yl)methyl)-4-oxo-3,4-dihydrophthalazin-1-yl)-3methoxyacrylate (7i). 


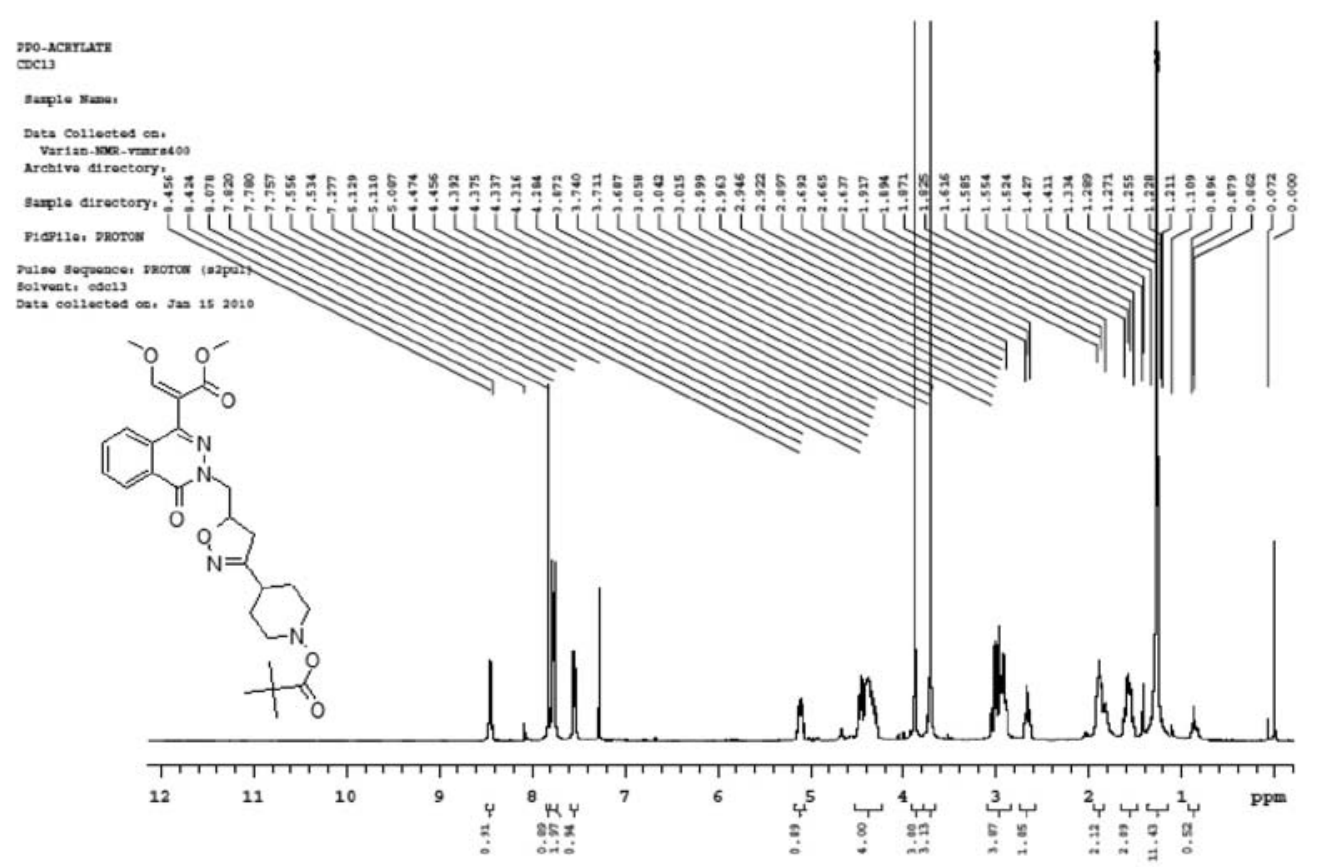

Figure S20. ${ }^{1} \mathrm{H}$ NMR spectrum of methyl 3-methoxy-2-(4-oxo-3-((3-(1-pivaloylpiperidin-4-yl)-4,5-dihydroisoxazol-5-yl)methyl)-3,4-dihydrophthalazin1-yl)acrylate (7j).

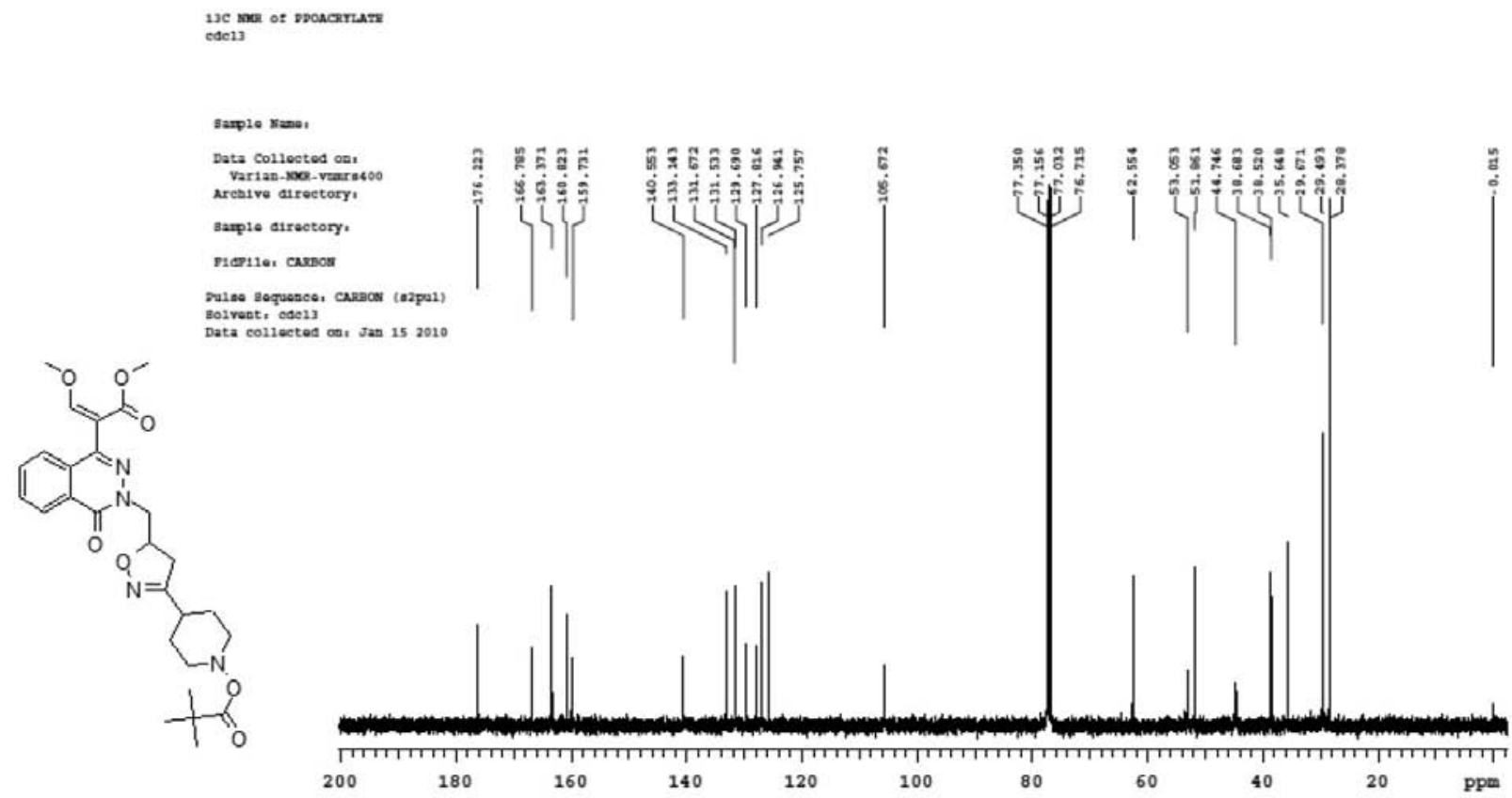

Figure S21. ${ }^{13}$ C NMR spectrum of methyl 3-methoxy-2-(4-oxo-3-((3-(1-pivaloylpiperidin-4-yl)-4,5-dihydroisoxazol-5-yl)methyl)-3,4-dihydrophthalazin1-yl)acrylate (7j). 


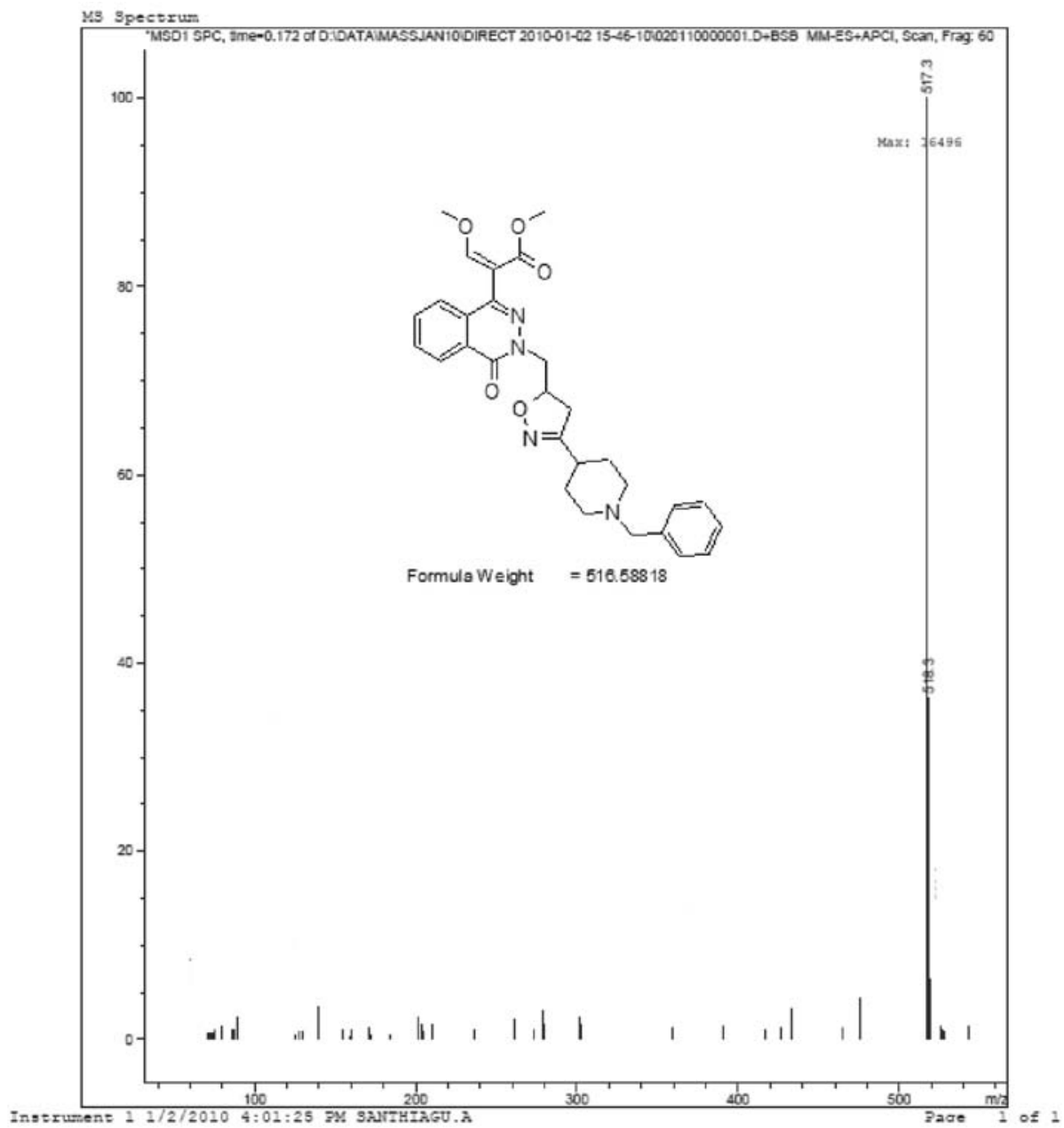

Figure S22. Mass spectrum of methyl 2-(3-((3-(1-benzylpiperidin-4-yl)-4,5-dihydroisoxazol-5-yl)methyl)-4-oxo-3,4-dihydrophthalazin-1-yl)-3methoxyacrylate (7k). 


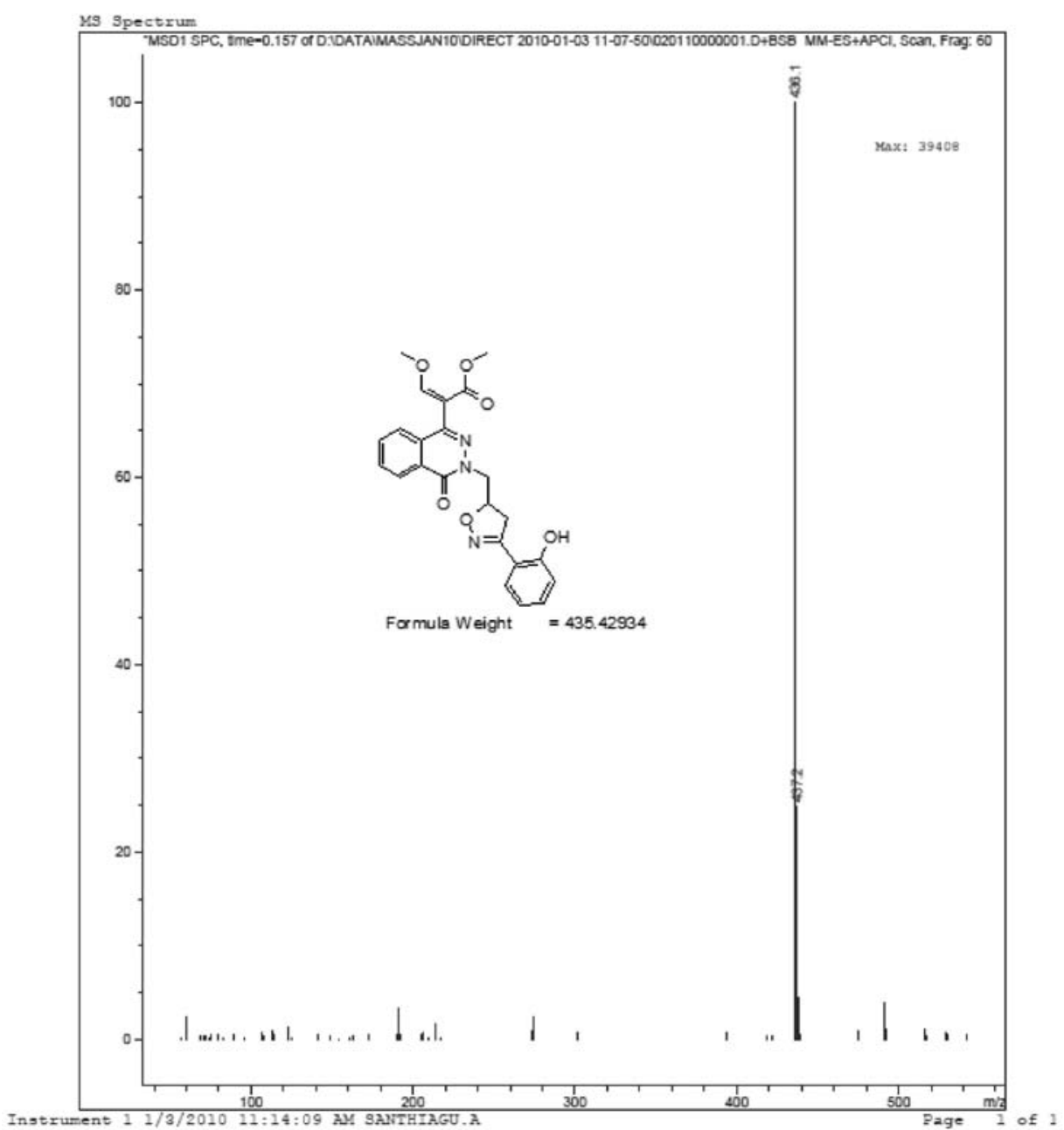

Figure S23. Mass spectrum of methyl 2-(3-((3-(2-hydroxyphenyl)-4,5-dihydroisoxazol-5-yl)methyl)-4-oxo-3,4-dihydrophthalazin-1-yl)-3-methoxyacrylate (7l).

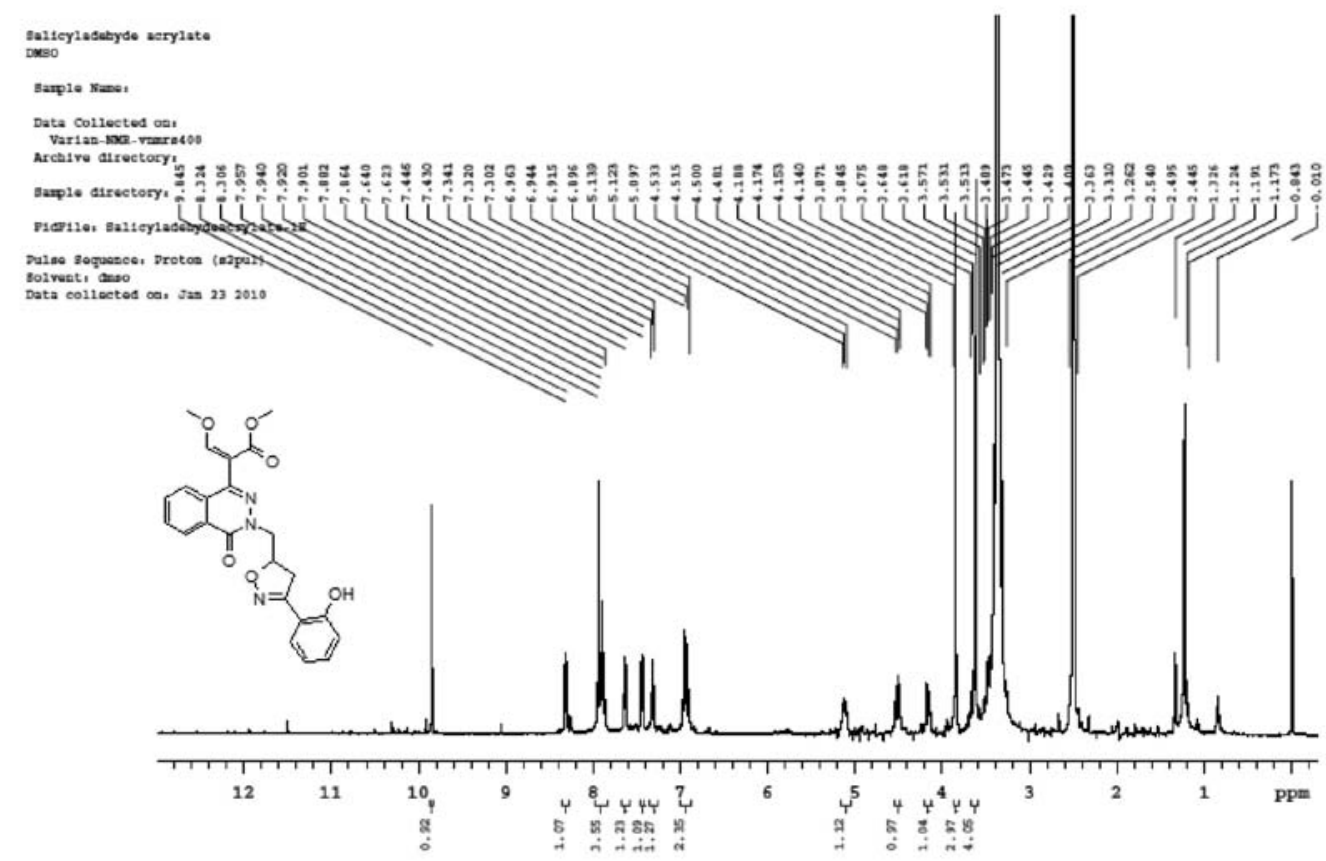

Figure S24. 'H NMR spectrum of methyl 2-(3-((3-(2-hydroxyphenyl)-4,5-dihydroisoxazol-5-yl)methyl)-4-oxo-3,4-dihydrophthalazin-1-yl)-3methoxyacrylate (71). 